\title{
The Involvement of Jasmonic Acid, Ethylene, and Salicylic Acid in the Signaling Pathway of Clonostachys rosea-Induced Resistance to Gray Mold Disease in Tomato
}

\author{
Qiuying Wang, ${ }^{1}$ Xiuling Chen, ${ }^{2}$ Xinfeng Chai, ${ }^{1}$ Dongqi Xue, ${ }^{3}$ Wei Zheng, ${ }^{2}$ Yuying Shi, ${ }^{2}$ and Aoxue Wang $1,2, \dagger$ \\ ${ }^{1}$ College of Life Science, Northeast Agricultural University, Harbin 150030, China \\ ${ }^{2}$ College of Horticulture and Landscape Architecture, Northeast Agricultural University, Harbin 150030, China \\ ${ }^{3}$ College of Horticulture, Henan Agricultural University, Zhengzhou 450000, China \\ Accepted for publication 11 March 2019.
}

\begin{abstract}
Tomato gray mold disease caused by Botrytis cinerea is a serious disease that threatens tomato production around the world. Clonostachys rosea has been used successfully as a biocontrol agent against divergent plant pathogens, including $B$. cinerea. To understand the signal transduction pathway of $C$. rosea-induced resistance to tomato gray mold disease, the effects of $C$. rosea on gray mold tomato leaves along with changes in the activities of three defense enzymes (phenylalanine ammonialyase [PAL], polyphenol oxidase [PPO], and catalase [CAT]), second messengers (nitric oxide $[\mathrm{NO}]$, hydrogen peroxide $\left[\mathrm{H}_{2} \mathrm{O}_{2}\right]$, and superoxide anion radical $\left[\mathrm{O}_{2}^{-}\right]$), and stress-related genes (mitogenactivated protein kinase [MAPK], WRKY, Lexyl2, and atpA) in four different hormone-deficient (jasmonic acid [JA], ethylene [ET], salicylic acid [SA], and gibberellin) tomato mutants were investigated. The results

lower levels of CAT activities in tomato leaves. Moreover, it also increased $\mathrm{NO}, \mathrm{H}_{2} \mathrm{O}_{2}$, and $\mathrm{O}_{2}{ }^{-}$levels and the gene expression levels of WRKY, MAPK, atpA, and Lexyl2. The incidence of gray mold disease in four hormone-deficient mutants was higher than that in the corresponding wild-type tomato plants. Among all of these hormone-deficient tomato mutants, JA had the most significant effect in regulating the different signal molecules. Additional study suggested that JA upregulated the expression of Lexyl2, MAPK, and WRKY but downregulated atpA. Furthermore, JA also enhanced the activity of PAL, PPO, and CAT and the production of $\mathrm{NO}$ and $\mathrm{H}_{2} \mathrm{O}_{2}$. SA downregulated CAT and PAL, whereas ET upregulated PAL but downregulated CAT. This study is of significance in understanding the regulatory pathways and biocontrol mechanism of $C$. rosea against $B$. cinerea.
\end{abstract} revealed that $C$. rosea significantly inhibited the growth of mycelia and spore germination of $B$. cinerea. Furthermore, it reduced the incidence of gray mold disease, induced higher levels of PAL and PPO, and induced
Keywords: biological control, disease control and pest management, mycology
Tomato (Solanum lycopersicum) is a major herbaceous vegetable worldwide that is susceptible to damage from pests (insects, mites, nematodes, and so on) as well as fungal, bacterial, or viral diseases. Tomato gray mold disease is one of the major diseases that threatens tomato production, and it is caused by the fungus Botrytis cinerea. This disease can infect not only tomato fruits but also, tomato leaves, stems, flowers, and other parts, rapidly spreading after the onset of infection (Masmoudi et al. 2017). B. cinerea is a necrotrophic plant pathogen that is able to infect $>1,400$ plant species (Elad et al. 2015), including tomato, carrot, cucumber, lettuce, eggplant, grape, apple, pear, cherry, strawberry, kiwi, and so on (Lemonnier et al. 2014). B. cinerea infection also activates the accumulation of reactive oxygen species (ROS) and cell death with hallmarks of programmed cell death (PCD) in plant tissues (Ponce et al. 2012). During the infection process, $B$. cinerea secretes cell wall-degrading enzymes (CWDEs), allowing the fungus to penetrate the surface of healthy plants (García et al. 2017). CWDEs may also cause plant cells to undergo PCD, facilitating the growth

†Corresponding author: A. Wang; axwang@neau.edu.cn

Funding: This work was supported by National Natural Science Foundation of China grant 31872120, National Key R\&D Program of China 2017 YFE0105000 and The Harbin Applied Technology Research and Development Project 2016RAXXJ051 (Excellent Academic Leader).

*The $\boldsymbol{e}$-Xtra logo stands for "electronic extra" and indicates that two supplementary figures are published online.

The author(s) declare no conflict of interest.

(c) 2019 The American Phytopathological Society of this necrotrophic fungus in dead plant tissues (Celedonio et al. 2016; Mengiste 2012).

Several fungicides have been used to effectively control this disease, especially at the preharvest stage. However, the excessive use of chemical fungicides has contributed to biodiversity impoverishment and negative environmental impact. Furthermore, this also induces fungicide resistance and problems for public health (Gajera and Vakharia 2010). Biological control (biocontrol), which uses antimicrobial agents to limit pathogen infections and activate the plant's own defense system, provides an attractive alternative for managing plant diseases. It is highly efficient and causes no harm to the environment or human health.

The fungus Clonostachys rosea has been an attractive biocontrol agent. It protects plants against $B$. cinerea by suppressing gray mold growth and inhibiting spore production (Mouekouba et al. 2014). The treatment of $B$. cinerea infection with $C$. rosea induces several defense mechanisms in tomato, including the fortification of the plant cell wall through the incorporation of phenolic compounds. Several signaling molecules have been identified in plant defense mechanisms, including phytohormones, such as indole acetic acid, abscisic acid, gibberellins (GAs), zeatin, jasmonic acid (JA), salicylic acid (SA), ethylene (ET), and ROS, which are mainly nitric oxide (NO), hydrogen peroxide $\left(\mathrm{H}_{2} \mathrm{O}_{2}\right)$, and superoxide anion radical $\left(\mathrm{O}_{2}^{-}\right)$, as well as several protective enzymes, such as phenylalanine ammonialyase (PAL), polyphenol oxidase (PPO), and catalase (CAT). These molecules trigger changes in the expression of defense genes, resulting in metabolic alterations that enhance plant defense responses (Mai et al. 2014; Quazi et al. 2015). Among all phytohormones, changes in JA, ET, SA, and GA were the most obvious in gray mold tomato leaves after $C$. rosea treatment (Mouekouba et al. 2014; Wang 2013). The expression of the WRKY 
transcription factor and mitogen-activated protein kinase $(M A P K)$ genes was also induced by different biotic and abiotic stresses in numerous plant species (Berri et al. 2009; Ramamoorthy et al. 2008; Zhang et al. 2007), suggesting that these genes may act as regulators for stress response. In addition, $B$. cinerea plus $C$. rose $a$ treatment in tomato leaves could induce higher expression levels of $\beta$-xylanase (Lexyl2) and ATP synthase CF1 $\alpha$-subunit (atpA) compared with other treatments (Mouekouba et al. 2014). These signaling molecules drive different plant signal transduction pathways through complicated interactions that function independently. In this study, the effects of $C$. rosea on gray mold tomato leaves were investigated using various tomato mutants involved in plant responses to biotic and abiotic stresses. Different phytohormonedeficient mutant tomato leaves were inoculated with $B$. cinerea and $C$. rosea to identify the mechanism by which changes in the signaling molecule and defense enzyme activity induce resistance. The results of this study can help us elucidate the innate immunity mechanisms of C. rosea and understand the regulatory relationship between key signal factors involved in plant defenses.

\section{MATERIALS AND METHODS}

Microbial culture and tomato plant growth. C. rosea was isolated from turfy soil in the suburbs of Jilin City (the northeast region of China) and confirmed by the $5.8 \mathrm{~S}$ ribosomal DNA (rDNA)-ITS and 18S rDNA sequences. The strain was deposited into the China General Microbiological Culture Collection Center. C. rosea was cultured on potato dextrose agar (PDA) plates at $22^{\circ} \mathrm{C}$. $B$. cinerea was isolated from infected tomato plants grown in a greenhouse (Wang 2013) and cultured on PDA at $25^{\circ} \mathrm{C}$.

Four hormone-related tomato mutants and their associated wild types were used for this study (Table 1). The plants were grown in a mixture of perlite/vermiculite/plant ash (1:6:2) in an artificial climate chamber (model: FYS-HY-7; Nanjing Hengyu Instrument Manufacturing Co., Ltd.). The day and night temperatures were 28 and $18^{\circ} \mathrm{C}$, respectively, under a 16 -h light and 8-h dark regime. Humidity was maintained at $80 \%$.

Antagonistic experiment in vitro. To test the antagonistic effect of $C$. rosea against $B$. cinerea, $C$. rosea and $B$. cinerea were first cultured separately on PDA at $28^{\circ} \mathrm{C}$ for 15 days. A 5-mm sterile hole puncher was used to collect the fresh mycelium of $C$. rosea or $B$. cinerea from the culture. The $C$. rosea and $B$. cinerea cells were inoculated to opposite sides of a 90-mm petri dish filled with PDA. The distance between these two strains was $40 \mathrm{~mm}$. The PDA plates were incubated at $28^{\circ} \mathrm{C}$, and the inhibitory effect was observed every day for a total of 15 days. Plates only inoculated with $B$. cinerea were used as a control. The inhibition rate of $C$. rosea to $B$. cinerea was calculated at 15 days after inoculation according to the following formula (Zong et al. 2003):

Inhibition $\operatorname{rate}(\%)=[$ radius of the control colony

- radius of $B$. cinerea colony confronted with

C. rosea)/radius of the control colony] $\times 100 \%$

The experiment was repeated three times, and at least six plates were used in each experiment (three plates for $B$. cinerea only [control] and three plates for B. cinerea plus $C$. rosea).
Effect of $C$. rosea on the spore germination of $B$. cinerea. The fermentation filtrate of $C$. rosea was prepared as follows. Mycelial scrapes from colonized plates were inoculated into a 250 -ml flask filled with potato dextrose broth (PDB; $200 \mathrm{~g}$ of peeled potato, $20 \mathrm{~g}$ of glucose, and $1,000 \mathrm{ml}$ of distilled water) and cultured at $28^{\circ} \mathrm{C}$ for $48 \mathrm{~h}$ with constant agitation $(200 \mathrm{r} / \mathrm{min})$. Then, the fermentation broth was centrifuged for $20 \mathrm{~min}\left(10,000 \times \mathrm{g} / \mathrm{min}\right.$ at $\left.4^{\circ} \mathrm{C}\right)$, and the supernatant was filtrated using a $0.22-\mu \mathrm{m}$ filter. The sterile fermentation filtrate was maintained at $4^{\circ} \mathrm{C}$ before use. The $B$. cinerea spore germination was carried out as previously described (Liu et al. 2013; Shu et al. 2004). Briefly, B. cinerea spore suspension was added to the sterile fermentation filtrate to a final concentration of 106 spores per $1 \mathrm{ml}$. One drop of the mixture was placed on a coverslip precoated with collodion. Then, the coverslip was placed on a moisturized petri dish and cultured for $10 \mathrm{~h}$ at $28^{\circ} \mathrm{C}$. The fermentation filtrate was replaced with fresh PDB medium as a control. Germination was defined when the length of the spore tube was longer than that of the spore diameter. The inhibition rate of spore germination $=$ (spore germination rate of the control - spore germination rate of the treated group)/spore germination rate of the control $\times 100 \%$.

Resistance of tomato plants to $B$. cinerea induced by C. rosea. The inoculation of tomato plants with $B$. cinerea and C. rosea was described in Abuqamar et al. (2008). Briefly, the $B$. cinerea or $C$. rosea conidia were suspended in distilled water to a final concentration of $1 \times 10^{7}$ spores per $1 \mathrm{ml}$. The 4-week-old tomato plants were first inoculated with $B$. cinerea conidia suspension (B group) by spraying these directly onto the leaves. $C$. rosea conidia suspension was inoculated at $12 \mathrm{~h}$ after the inoculation of $B$. cinerea $(\mathrm{B}+\mathrm{C}$ group). The same volume of water (no B. cinerea or $C$. rosea) was used as a control (CK group). At 18 days after inoculation with $B$. cinerea, the incidence of gray mold disease was investigated, and the disease index was calculated as previously reported (Fang 2007).

Leaf samples were collected from inoculated plants every $12 \mathrm{~h}$ ( 0 to $96 \mathrm{~h}$ ) and stored at $-80^{\circ} \mathrm{C}$ for enzyme activity assay (refer to the next section). Leaves from at least 10 individual plants were used in each independent experiment. Each experiment was repeated three times.

Enzyme activity assay of PAL, PPO, and CAT in tomato leaves. Leaf samples were collected as described above. Then, $0.5 \mathrm{~g}$ of leaves from each sample were used for protein extraction. The leaf sample was rinsed in ice cold phosphate buffer ( $\mathrm{pH} 7.4$ ), dried with filter paper, and placed in $2 \mathrm{ml}$ of ice cold homogenate medium provided in the enzyme activity kits (Nanjing Institute of Biological Engineering). Then, the leaf tissue was cut into small pieces, homogenized, and filtered through a cheesecloth. Afterward, the solution was centrifuged at 4,000 rpm for $15 \mathrm{~min}$, and the supernatant was used as the enzyme source. Next, the protein concentrations were measured using a commercial protein assay kit (catalog number CW0014; Beijing Kangwei Century Biotechnology Co., Ltd.). The activities of PAL and PPO were carried out using commercially available kits for PAL and PPO (Nanjing Institute of Biological Engineering) according to the manufacturer's instruction. CAT activity was detected as previously described (Li 2000).

Determination of second messengers: $\mathrm{NO}, \mathrm{H}_{2} \mathrm{O}_{2}$, and $\mathbf{O}_{2}^{-}$. The assays for $\mathrm{NO}, \mathrm{H}_{2} \mathrm{O}_{2}$, and $\mathrm{O}_{2}^{-}$were carried out using commercially available $\mathrm{NO}(\mathrm{A} 013-1), \mathrm{H}_{2} \mathrm{O}_{2}$ (A064), and $\mathrm{O}_{2}^{-}$assay

TABLE 1. Hormone-related tomato mutants and the associated wild types used in the study

\begin{tabular}{|c|c|c|c|}
\hline Mutants & Mutation & Wild type & Cultivar origin \\
\hline Spr2 (jasmonic acid deletion mutant) & $\begin{array}{l}\text { Jasmonate biosynthetic } \\
\text { pathway blocked }\end{array}$ & $\begin{array}{l}\text { CM (Le. CM indicate the } \\
\text { wild-type of } S p r 2 \text { ) }\end{array}$ & $\begin{array}{l}\text { Institute of Genetics and Developmental } \\
\text { Biology, Chinese Academy of Sciences }\end{array}$ \\
\hline Nor (ethylene deletion mutant) & $\begin{array}{l}\text { Ethylene biosynthetic } \\
\text { pathway blocked }\end{array}$ & $\begin{array}{l}\text { AC (Ailsa Craig indicates the } \\
\text { wild-type of nor) }\end{array}$ & Tomato Genetics Resource Center \\
\hline $\begin{array}{l}\text { NahG (salicylic acid deletion } \\
\text { mutant) }\end{array}$ & $\begin{array}{l}\text { Salicylic acid } \\
\text { biosynthetic } \\
\text { pathway blocked }\end{array}$ & $\begin{array}{l}\text { MM (Moneymaker indicates the } \\
\text { wild-type of } N a h G \text { ) }\end{array}$ & $\begin{array}{l}\text { Horticultural Institute of Shenyang } \\
\text { Agricultural University }\end{array}$ \\
\hline Gib3 (gibberellin deletion mutant) & $\begin{array}{l}\text { Gibberellin biosynthetic } \\
\text { pathway blocked }\end{array}$ & $\begin{array}{l}\text { MM (Moneymaker indicates the } \\
\text { wild-type of Gib3) }\end{array}$ & Tomato Genetics Resource Center \\
\hline
\end{tabular}


kits (A052; all were obtained from Nanjing Institute of Biological Engineering) according to the manufacturer's protocols. The sample protein concentration was measured using a commercial protein assay kit (catalog number CW0014; Beijing Kangwei Century Biotechnology Co., Ltd.).

Real-time polymerase chain reaction of $M A P K, W R K Y$, atpA, and Lexyl2 genes. The leaf samples obtained from different treatments were collected as described above. Total RNA was extracted using Trizol reagent (Invitrogen) according to the manufacturer's instructions. Total RNA was dissolved in $20 \mu \mathrm{l}$ of RNase-free $\mathrm{H}_{2} \mathrm{O}$ and quantified by spectrophotometry. The total RNA extracted from the triplicate of tomato leaves was reverse transcribed using the Easyscript first-strand complementary DNA synthesis super mix (Beijing Transgen Biotech Co. Ltd., Beijing, China) according to the manufacturer's instructions and stored at $-80^{\circ} \mathrm{C}$.

The polymerase chain reaction (PCR) conditions are listed in Tables 2, 3, and 4. The primers were designed as previously described (Mouekouba et al. 2014). These are listed in Table 5. $\beta$-actin was used as a control. PCR was carried out using the iCycler real-time quantity PCR system (Bio-Rad). The relative expression was calculated using the $2^{-\Delta \Delta C t}$ method as previously described (Livak and Schmittgen 2001). These experiments were repeated independently with three biological replicates.

Scanning electron microscopy observation. At 0 (control), $2,4,6,8,10$, and 12 days after the inoculation of gray mold, leaf samples were collected for scanning electron microscopy (SEM) analysis. A small square of 1 to $2 \mathrm{~mm}^{2}$ of the leaf (Spr2 and CM [Le. $\mathrm{CM}]$ ) was cut between the veins and the edge. The SEM samples were prepared as previously described (Hao et al. 2017). An S$3400 \mathrm{~N}$ scanning electron microscope (Hitachi) was used to observe and image the samples. A total of 30 images were taken from each sample at magnifications of $600 \times$ and $1,200 \times$. Stomatal opening rate $=($ stomatal opening number $) /($ total stomatal number $) \times 100 \%$.

Transmission electron microscopy observation. The sample collection for transmission electron microscopy (TEM) was the same as that for SEM. The collected samples were prepared for TEM observation as previously described (Gong 2017). An

TABLE 2. Polymerase chain reaction mix

\begin{tabular}{lc}
\hline Materials & Volume, $\mu \mathrm{l}$ \\
\hline Bio-Rad Super SYBR Green mix & 10 \\
Primer F $(10 \mu \mathrm{M})$ & 0.4 \\
Primer R $(10 \mu \mathrm{M})$ & 0.4 \\
Template complementary DNA $(25 \mathrm{ng})$ & 2 \\
$\mathrm{ddH}_{2} \mathrm{O}$ (double distilled water) & 7.2 \\
Total volume & 20 \\
\hline
\end{tabular}

TABLE 3. Polymerase chain reaction conditions for the mitogen-activated protein kinase and $W R K Y$ genes

\begin{tabular}{lccc}
\hline Stage & Cycles & Temperature, ${ }^{\circ} \mathrm{C}$ & Time \\
\hline Stage 1 & 1 & 94 & $5 \mathrm{~min}$ \\
Stage 2 & 35 & 94 & $30 \mathrm{~s}$ \\
& & 55 & $30 \mathrm{~s}$ \\
Stage 3 & 72 & $60 \mathrm{~s}$ \\
\hline
\end{tabular}

TABLE 4. Polymerase chain reaction conditions for the atpA and Lexyl2 genes

\begin{tabular}{lccc}
\hline Stage & Cycles & Temperature, ${ }^{\circ} \mathrm{C}$ & Time \\
\hline Stage 1 & 1 & 94 & $3 \mathrm{~min}$ \\
Stage 2 & 35 & 95 & $45 \mathrm{~s}$ \\
& & 52 & $45 \mathrm{~s}$ \\
Stage 3 & 72 & $60 \mathrm{~s}$ \\
\hline
\end{tabular}

H-7650 transmission electron microscope (Hitachi) was used to observe the ultrastructure of mesophyll cells and chloroplasts.

Statistical analysis. All data were presented as mean \pm standard deviation. The statistical analysis was performed with one-way analysis of variance (SPSS software, v.20; SPSS Inc.). The separations were performed using Duncan's multiple range tests. Differences at $P<0.05$ were considered to be statistically significant. Student's $t$ test was used to compare the resistance of tomato with $B$. cinerea induced by $C$. rosea between treatments. All of the experiments were repeated three times.

\section{RESULTS}

$C$. rosea inhibits the colony growth of $B$. cinerea. The possible inhibition role of $C$. rosea toward $B$. cinerea was examined. In the absence of $C$. rosea, $B$. cinerea grew well on the PDA plate, reaching a radius of $27.6 \pm 0.92 \mathrm{~mm}$ after 15 days of culture. The colony appeared to be grayish brown and formed many small granular dark sclerotia (Fig. 1G). In the presence of $C$. rosea, the $B$. cinerea grew much slower, reaching a radius of $1.81 \pm 0.31 \mathrm{~mm}$ at day 4 (Fig. 1A, C, and E). However, the C. rosea colony continued to grow and enlarge, and it completely inhibited the growth of B. cinerea after 15 days of culture (Fig. $1 \mathrm{~B}, \mathrm{D}$, and $\mathrm{F}$ ). The colony of $B$. cinerea became even smaller, with a radius of $0.3 \pm 0.03 \mathrm{~mm}$, suggesting that the $B$. cinerea hyphae were degraded and engulfed by $C$. rosea possibly by substances released by $C$. rosea. Finally, the $B$. cinerea was completely covered by $C$. rosea, causing its degradation and death. At the contact area between $C$. rosea and $B$. cinerea, a bacteriostatic ring was clearly observed (Fig. 1B and C). The calculated inhibition rate at 15 days was $98.91 \pm 0.13 \%$.

The germination of $B$. cinerea was also inhibited by $C$. rosea. When cultured in fresh PDB medium, the germination rate of $B$. cinerea reached up to $36.73 \pm 0.98 \%$, but it only reached $2.25 \pm$ $0.13 \%$ when cultured in the $C$. rosea fermentation filtrate. The inhibition rate of spore germination by the $C$. rosea fermentation filtrate was $93.87 \pm 0.44 \%$. Among the geminated spores, the tubes were much longer in the fresh PDB medium than in the $C$. rosea fermentation filtrate (Fig. 2).

$C$. rosea enhances the resistance of tomato plants to B. cinerea. Next, the possible effect of $C$. rosea in enhancing the resistance of tomato plants to $B$. cinerea was examined. Compared with the control group, the $B$. cinerea-treated groups (both wild type and mutants) grew slower, and the gray mold disease indexes were significantly higher (Fig. 3), indicating that B. cinerea impairs tomato growth. Treatment with $C$. rosea significantly improved tomato growth and significantly decreased the gray mold disease. In all types of tomato plants, the averages of plant heights and leaf numbers of the $\mathrm{B}+\mathrm{C}$ group were at least one time higher than those of the B group. This is consistent with a previous report from our laboratory (Wang et al. 2015). Leaf lesions were also significantly

TABLE 5. Primers used for the polymerase chain reaction amplification

\begin{tabular}{ll}
\hline Gene and primer & \multicolumn{1}{c}{ Sequence } \\
\hline $\begin{array}{l}\text { Mitogen-activated protein kinase } \\
\text { Forward primer }\end{array}$ & GCTGACAGATTGTTGCAGGT \\
Reverse primer & TCCACCCCATAAAGATACATCA \\
WRKY & GCATTACTGTCAACCATCGC \\
Forward primer & AACTTCGCGGATTCTCACTT \\
Reverse primer & \\
atpA & AGGCTCATATACGGAACGG \\
Forward primer & GAGTGAGGCTTATTTGGGTC \\
Reverse primer & \\
Lexyl2 & GTGGTGCTGCGTTGGCTGA \\
Forward primer & GTGGTGTTTGTATTGGGTGT \\
Reverse primer & \\
$\beta$-actin & TGTCCCTATTTACGAGGGTTATGC \\
Forward primer & CAGTTAAATCACGACCAGCAAGAT \\
Reverse primer & \\
\hline
\end{tabular}


different among these three groups. Almost no lesions were observed in the control group. Furthermore, leaves in the $\mathrm{B}+\mathrm{C}$ group had fewer leaf spots, whereas leaves in the B group were covered with gray brown spots and large lesion sizes. In addition, the incidence of gray mold disease in the four hormone-deficient mutants was significantly higher compared with that in corresponding wild-type tomato plants, suggesting that deficiency in the production of these hormones affects the host resistance to $B$. cinerea.

$C$. rosea improves the ultrastructure of $B$. cinereainfected tomato leaf cells. To confirm that $C$. rosea could enhance the resistance of tomato plants to $B$. cinerea, the ultrastructure of tomato leaves was examined under different treatments. After 5 days of $B$. cinerea inoculation, the ultrastructure of the green tissue on the edge of the disease spot of a tomato leaf was severely injured in both the wild type and the JA mutant (Spr2) (Supplementary Fig. S1).

In the JA mutant (Spr2), chloroplasts became round, and the starch granules became nearly full of whole chloroplasts. Furthermore, the grana were destroyed (blurred, reduced, and no lamellar structure), some mitochondria were degraded, thylakoid disintegration and partial dissolution occurred, and the separation of chloroplasts from the cell wall was observed. In the wild type, the membranes were degraded and ruptured, the chloroplasts became round, partial chloroplasts were degraded and ruptured, the grana were destroyed (loosely arranged, blurred, and reduced), thylakoids were stacked and partially dissolved, and chloroplast and cell wall separation occurred.

After 5 days of $B$. cinerea plus $C$. rosea inoculation, the ultrastructure of the green tissue at the edge of the spot significantly improved, although minor damage could still be observed. In the JA mutant, the morphology of chloroplasts was close to a spindle shape. Furthermore, the starch grains in the individual chloroplasts were bigger, the majority of granum lamellae were clearly visible, and the mitochondria had no obvious changes.

In the wild type, the chloroplast morphology remained intact. Although the starch grains were somewhat larger, there was no separation between the chloroplast and cell wall, and the chloroplast
A $4 d$

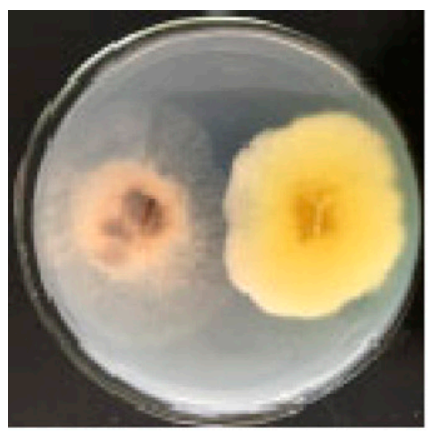

C $4 \mathrm{~d}$

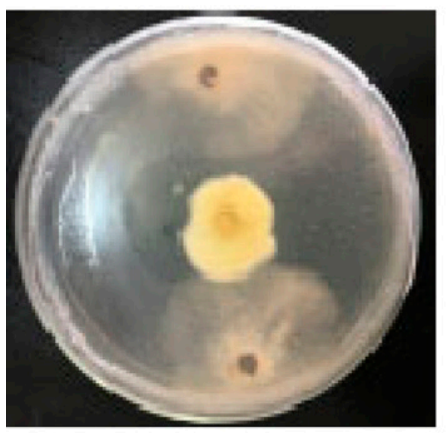

B1 $15 d$

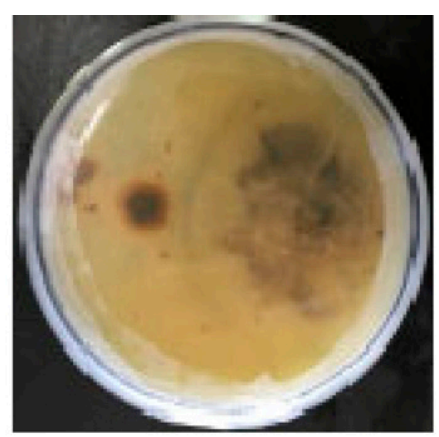

D1 $15 d$

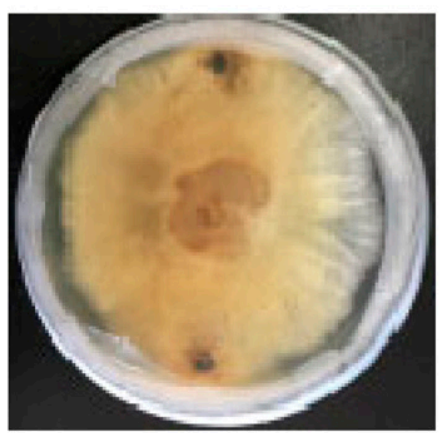

B2 $15 d$

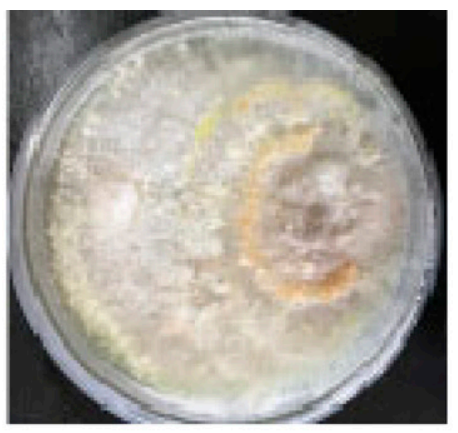

D2 $15 d$

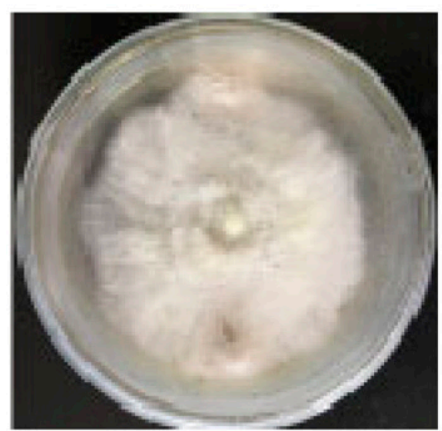

F2 $15 d$

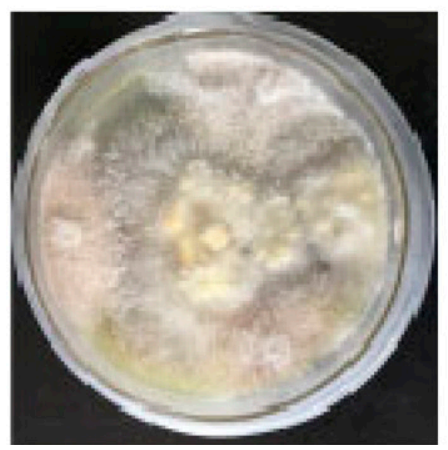

G

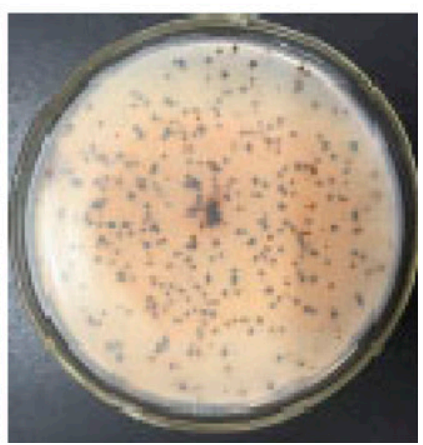

Fig. 1. The mycoparasitism of Clonostachys rosea to Botrytis cinerea in potato dextrose agar is shown. A, C, and E, At 4 days after inoculation with $C$. rosea and B. cinerea. B1, B2, D1, D2, F1, and F2, At 15 days after inoculation with C. rosea and B. cinerea. A, B1, and B2, Single-point, C, D1, and D2, double-point, and E, F1, and F2, triple-point inoculations of the antagonistic effect of $C$. rosea were evaluated: B1, D1, and F1 present the back side of the plate, whereas B2, D2, and $\mathbf{F} 2$ present the front side of the plate. G, Negative control: 15 days after inoculation only with $B$. cinerea (back side of the plate). 
granum lamellae had no obvious loosening degradation. Furthermore, some of the granum lamellae were clearly visible, and there was no obvious change in mitochondria.

Changes in activity of defense enzymes in response to B. cinerea and $C$. rosea treatment. Compared with controls,
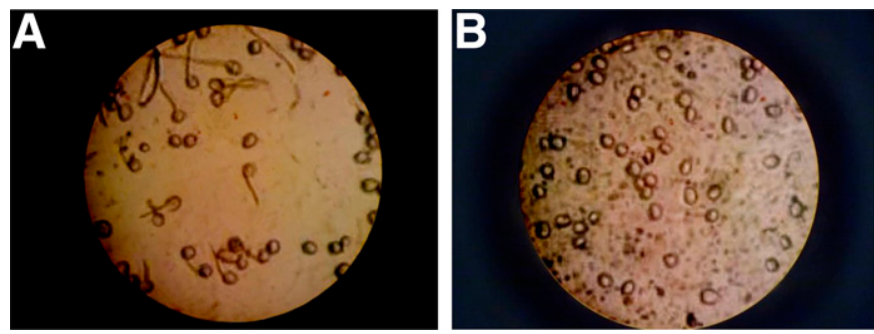

Fig. 2. Inhibition of the Clonostachys rosea fermentation solution against the spore germination of Botrytis cinerea $(100 \times)$ : $\mathbf{A}$, control and $\mathbf{B}$, treatment with the $C$. rosea fermentation solution.
B. cinerea treatment significantly increased the activities of PAL and PPO but decreased the activity of CAT in both the wild type and the four mutants. This was apparent in both the B group (treated with $B$. cinerea only) and the $\mathrm{B}+\mathrm{C}$ group (treated with B. cinerea and C. rosea).

The PAL activities reached their peaks at $\sim 60$ to $84 \mathrm{~h}$. The PAL activity of Spr2 (JA deletion) plants was higher than that of the wild type (CM) plants in the B group, but it was lower than that in the wild type of the B $+\mathrm{C}$ group (Fig. 4A). A similar trend was observed in the nor (ET deletion) mutant, where PAL activity reached its highest peak in the $\mathrm{B}+\mathrm{C}$ group at $84 \mathrm{~h}$ (Fig. 4B). For the NahG (SA deletion) and Gib3 (GA deletion) mutants, the PAL activities of these mutants were normally higher than those of the wild type (Moneymaker, MM) in both the B group and the $\mathrm{B}+\mathrm{C}$ group (Fig. $4 \mathrm{C}$ and D), suggesting that the $N a h G$ and Gib3 mutants have an opposite effect compared with Spr2 and nor.

In both the $\mathrm{B}$ and $\mathrm{B}+\mathrm{C}$ groups, PPO activities gradually increased, reached their peaks at $\sim 60$ to $84 \mathrm{~h}$, and subsequently decreased. The PPO activity of CM plants was mostly higher than that of Spr2 plants in both the B group and the B + C group. At $72 \mathrm{~h}$,
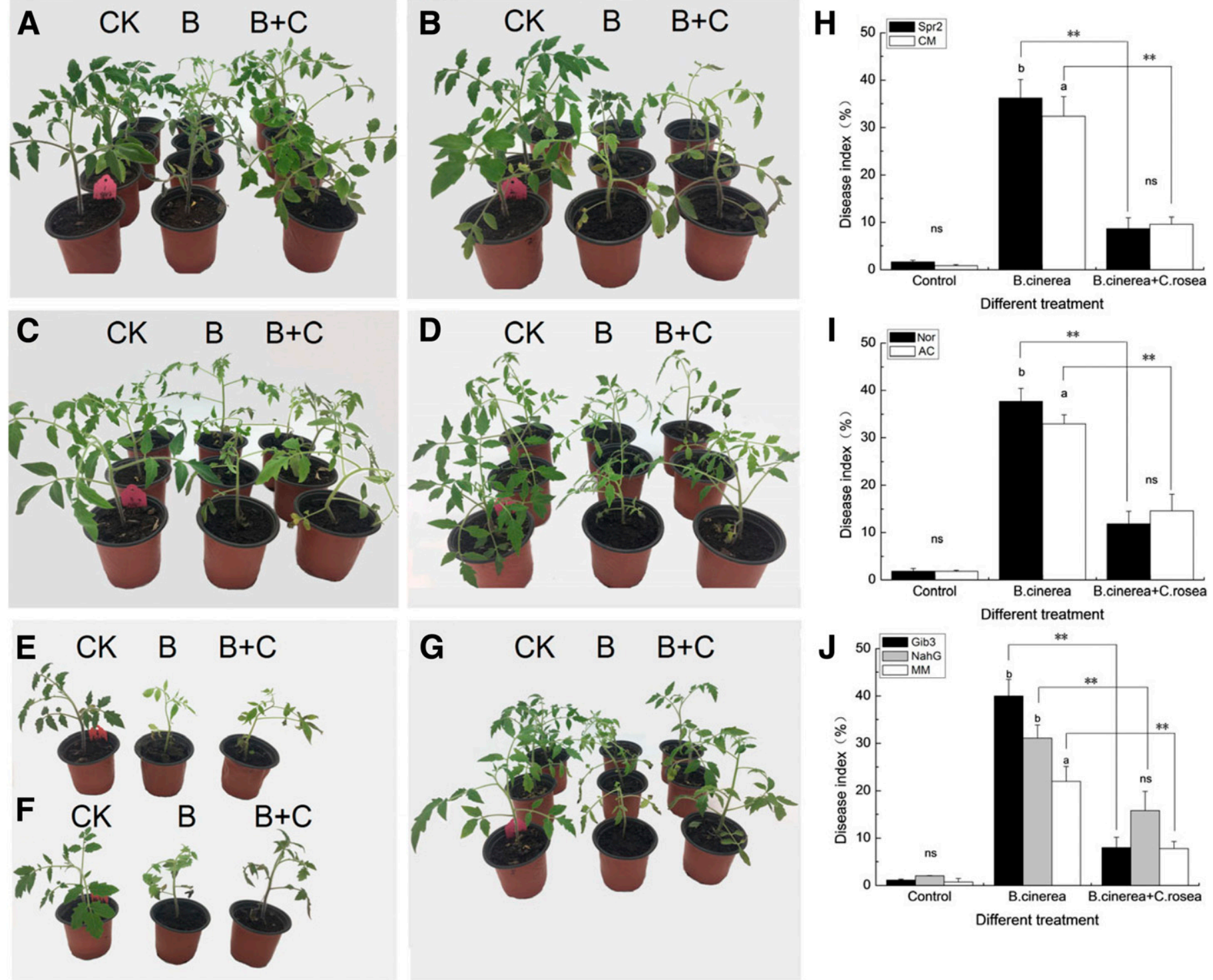

Fig. 3. Analysis of the spectral resistance of tomato to Botrytis cinerea primed by Clonostachys rosea. The incidence of gray mold disease in the different varieties was calculated at 18 days after inoculation with B. cinerea. A to G represent Spr2, CM (Le. CM), Nor, AC (Ailsa Craig), Gib3, NahG, and MM (Moneymaker), respectively. The $\mathrm{CK}$ (control check) row indicates the water treatment group, the $\mathrm{B}$ row indicates the $B$. cinerea conidia-treated group, and the $\mathrm{B}+\mathrm{C}$ row indicates the group first treated with $B$. cinerea conidia suspension and then, treated with $C$. rosea conidia suspension after $12 \mathrm{~h}$. $\mathbf{H}$ to $\mathbf{J}$ show the disease indexes of the $\mathbf{H}$, Spr2, I, Nor, and J, Gib3 and NahG mutants and their wild types. Each experiment was repeated three times for each treatment, with at least 15 strains of singletype tomato. The different letters show the significant difference at $P \leq 0.05$ by Duncan's multiple range. ns, not significant. $* * P<0.01$ versus $B$. cinerea plus $C$. rosea. 
the maximum value of $\mathrm{PPO}$ activity in $\mathrm{CM}$ leaves in the $\mathrm{B}+\mathrm{C}$ group was almost three times higher than that of the B group (Fig. 5A).

The PPO activity of the wild-type (Ailsa Craig, AC) plants was significantly higher than that of the nor plants at the 60- to 96-h time points but lower at the 24- and 48-h time points in the B group. In the $\mathrm{B}+\mathrm{C}$ group, the PPO activities of both nor and the wild type (AC) reached heir peaks at 36 and $60 \mathrm{~h}$, respectively, with maximum values of 145.9 and $191.9 \%$ higher than that of controls, respectively. The PPO
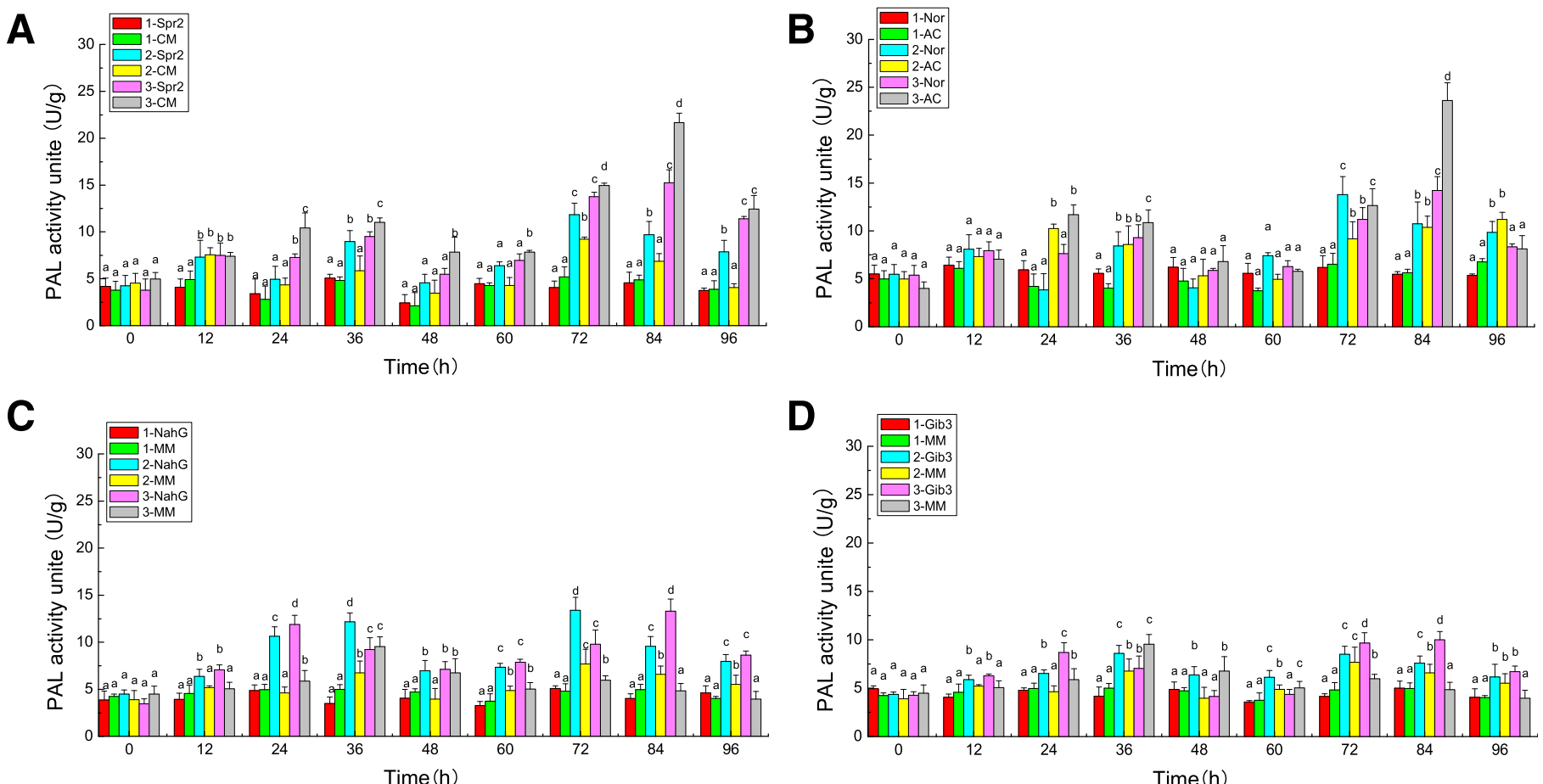

Fig. 4. Analysis of phenylalanine ammonialyase (PAL) activity. Changes in PAL levels in tomato leaves subjected to different treatments. Each experiment was repeated three times. Data are presented as mean \pm standard deviation. The means marked with different letters $(\mathbf{A}, \mathbf{B}, \mathbf{C}$, and $\mathbf{D})$ are significantly different at $P<$ 0.05. 1-Spr2, 1-CM (Le. CM), 1-Nor, 1-AC (Ailsa Craig), 1-NahG, 1-Gib3, and 1-MM (Moneymaker) indicate the control group (treated with water); 2-Spr2, 2$\mathrm{CM}, 2-\mathrm{Nor}, 2-\mathrm{AC}, 2-\mathrm{NahG}, 2-\mathrm{Gib3}$, and 2-MM indicate the B group (treated with Botrytis cinerea); and 3-Spr2, 3-CM, 3-Nor, 3-AC, 3-NahG, 3-Gib3, and 3-MM indicate the B + C group (treated with B. cinerea plus Clonostachys rosea). A, Spr2 mutant and wild-type CM tomato plant. B, nor mutant and wild-type AC tomato plant. C, NahG mutant and wild-type tomato plant. D, Gib3 mutant and wild-type MM tomato plant.
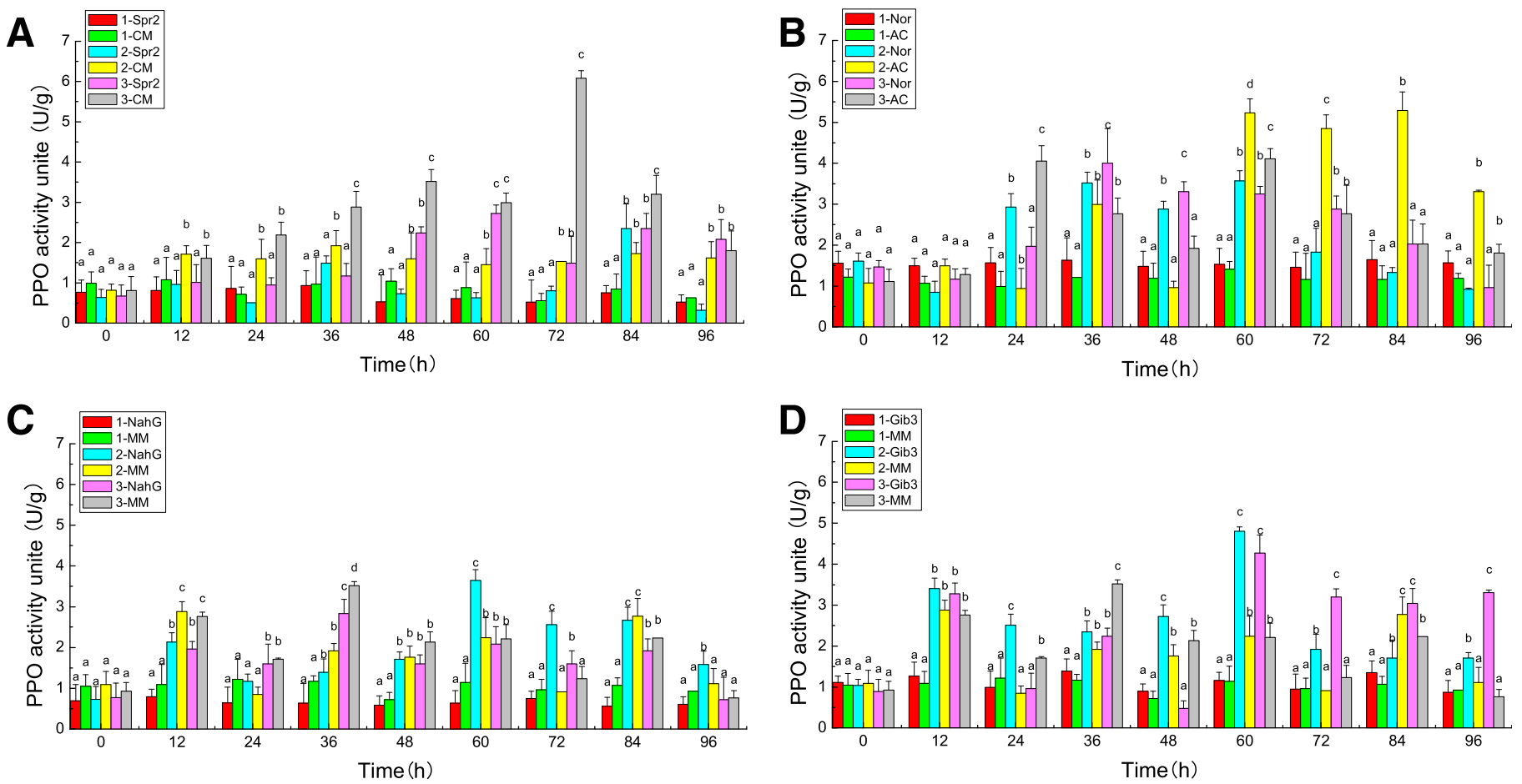

Fig. 5. Analysis of polyphenol oxidase (PPO) activity. Changes in PPO levels in tomato leaves subjected to different treatments. Each experiment was repeated three times. Data are presented as mean \pm standard deviation. The means marked with different letters $(\mathbf{A}, \mathbf{B}, \mathbf{C}$, and $\mathbf{D})$ are significantly different at $P<0.05$. 1 Spr2, 1-CM (Le. CM), 1-Nor, 1-AC (Ailsa Craig), 1-NahG, 1-Gib3, and 1-MM (Moneymaker) indicate the control group (treated with water); 2-Spr2, 2-CM, 2Nor, 2-AC, 2-NahG, 2-Gib3, and 2-MM indicate the B group (treated with Botrytis cinerea); and 3-Spr2, 3-CM, 3-Nor, 3-AC, 3-NahG, 3-Gib3, and 3-MM indicate the B + C group (treated with B. cinerea plus Clonostachys rosea). A, Spr2 mutant and wild-type CM tomato plant. B, nor mutant and wild-type AC tomato plant. C, $N a h G$ mutant and wild-type MM tomato plant. D, Gib3 mutant and wild-type MM tomato plant. 
activity of AC plants was significantly higher than that of nor plants at 24 and $60 \mathrm{~h}$ but lower at 36 and $48 \mathrm{~h}$ (Fig. 5B). Similar to PAL activities, the PPO activities of the $N a h G$ and Gib3 mutants were higher than the wild type (MM) in both the $\mathrm{B}$ group and the $\mathrm{B}+\mathrm{C}$ group (Fig. 5C and D).

Different from PAL and PPO activities, CAT activities decreased when treated with $B$. cinerea (in both the B group and the $\mathrm{B}+\mathrm{C}$ group). In the B group, the CAT activities of the Spr2 and the wild-type leaves reached their lowest levels at 36 and $24 \mathrm{~h}$, respectively, 65.9 and $30.7 \%$ lower than that of controls, respectively. Furthermore, the CAT activity of Spr2 plants was significantly lower than that of the wild-type $(\mathrm{CM})$ plants at three time points (36 to $60 \mathrm{~h}$ ). In the $\mathrm{B}+\mathrm{C}$ group, the CAT activities of the Spr2 and CM leaves reached their lowest levels at 36 and 60 h, respectively, 57.9 and $42.8 \%$ lower than that of controls, respectively. In both treatments, the CAT activity in Spr2 was lower than that in the wild type (Fig. 6A). In the B group, the CAT activities of the nor and the wild-type (AC) leaves reached their lowest levels at 72 and $36 \mathrm{~h}$, respectively, 73.2 and $74.9 \%$ lower than that of controls, respectively. Furthermore, the CAT activity of $\mathrm{AC}$ was significantly lower than that of nor in the $\mathrm{B}+\mathrm{C}$ group from 12 to $72 \mathrm{~h}$. In the $\mathrm{B}+\mathrm{C}$ group, the CAT activities of the nor and $\mathrm{AC}$ leaves reached their lowest levels at 48 and $60 \mathrm{~h}$, respectively, 65.3 and $79.1 \%$ lower than that of controls, respectively. The CAT activity of nor plants was significantly higher than that of AC plants at $60 \mathrm{~h}$ (Fig. 6B). Furthermore, the CAT activity of $N a h G$ was significantly higher than the wild type (MM) in both the $\mathrm{B}$ and the $\mathrm{B}+\mathrm{C}$ groups (Fig. 6C), but no significant difference in CAT activity was observed between the Gib3 and the wild-type (MM) plants (Fig. 6D).

Changes in second messenger levels in response to B. cinerea and $C$. rosea treatment. In the Spr2 mutant and its wild type $(\mathrm{CM})$, the $\mathrm{H}_{2} \mathrm{O}_{2}$ levels were relatively steady, except for the high level that increased at $72 \mathrm{~h}$ in the $\mathrm{B}+\mathrm{C}$ group, which gradually decreased to normal level (Fig. 7A). B. cinerea treatment increased the levels of $\mathrm{H}_{2} \mathrm{O}_{2}$ in the nor mutant in both the $\mathrm{B}$ and the $\mathrm{B}+\mathrm{C}$ groups, whereas the $\mathrm{H}_{2} \mathrm{O}_{2}$ level was higher in the wild type in the $\mathrm{B}+\mathrm{C}$ group compared with the mutant (Fig. 7B). Furthermore, $\mathrm{H}_{2} \mathrm{O}_{2}$ levels increased in the $N a h G$ mutant in both the $\mathrm{B}$ and the $\mathrm{B}+\mathrm{C}$ groups within 60 to $84 \mathrm{~h}$, whereas $\mathrm{H}_{2} \mathrm{O}_{2}$ levels were higher in the wild type compared with the mutant (Fig. 7C). A similar trend was also observed in the Gib3 mutant compared with the NahG mutant (Fig. 7D).

A similar change in NO levels was observed in all four mutants, in which $B$. cinerea treatment (both the $\mathrm{B}$ and the $\mathrm{B}+\mathrm{C}$ groups) induced a significant increase in NO within 60 to $84 \mathrm{~h}$ (Fig. 8). In the Spr2 and nor mutants, NO levels were higher in the wild type compared with the mutant, whereas in the Gib3 mutant, NO levels were higher in the mutant than in the wild type. However, in the NahG mutant, no significant difference in NO level was observed between the wild type and mutant.

A similar change in $\mathrm{O}_{2}^{-}$levels was also observed in all four mutants, in which $B$. cinerea treatment (both the $\mathrm{B}$ and the $\mathrm{B}+\mathrm{C}$ groups) caused a significant increase in $\mathrm{O}_{2}^{-}$at $24 \mathrm{~h}$ (Fig. 9). In the Spr2 mutant, the $\mathrm{O}_{2}^{-}$level was significantly higher in the mutant than in the wild type (Fig. 9A), whereas in the nor mutant, the $\mathrm{O}_{2}^{-}$level was higher in the wild type than in the mutant (Fig. 9B). However, in the $N a h G$ and Gib3 mutants, no significant difference in $\mathrm{O}_{2}^{-}$level was observed between the wild type and the mutant (Fig. 9C and D).

The expression of stress-related genes in response to $B$. cinerea and $C$. rosea treatment. $B$. cinerea treatment (both in the $\mathrm{B}$ and the $\mathrm{B}+\mathrm{C}$ groups) caused a significant increase of WRKY expression. However, this only occurred in the wild type (CM), and it did not occur in the Spr2 mutant (Fig. 10A). The highest WRKY expression was observed at $24 \mathrm{~h}$, in which the $\mathrm{B}+\mathrm{C}$ group exhibited a significantly higher $W R K Y$ expression compared with the $\mathrm{B}$ group.

Different from the $W R K Y$ expression, the $M A P K$ gene expression increased in both the wild type and the mutant (Spr2), but the MAPK gene expression in $S p r 2$ seemed to be significantly lower than that in
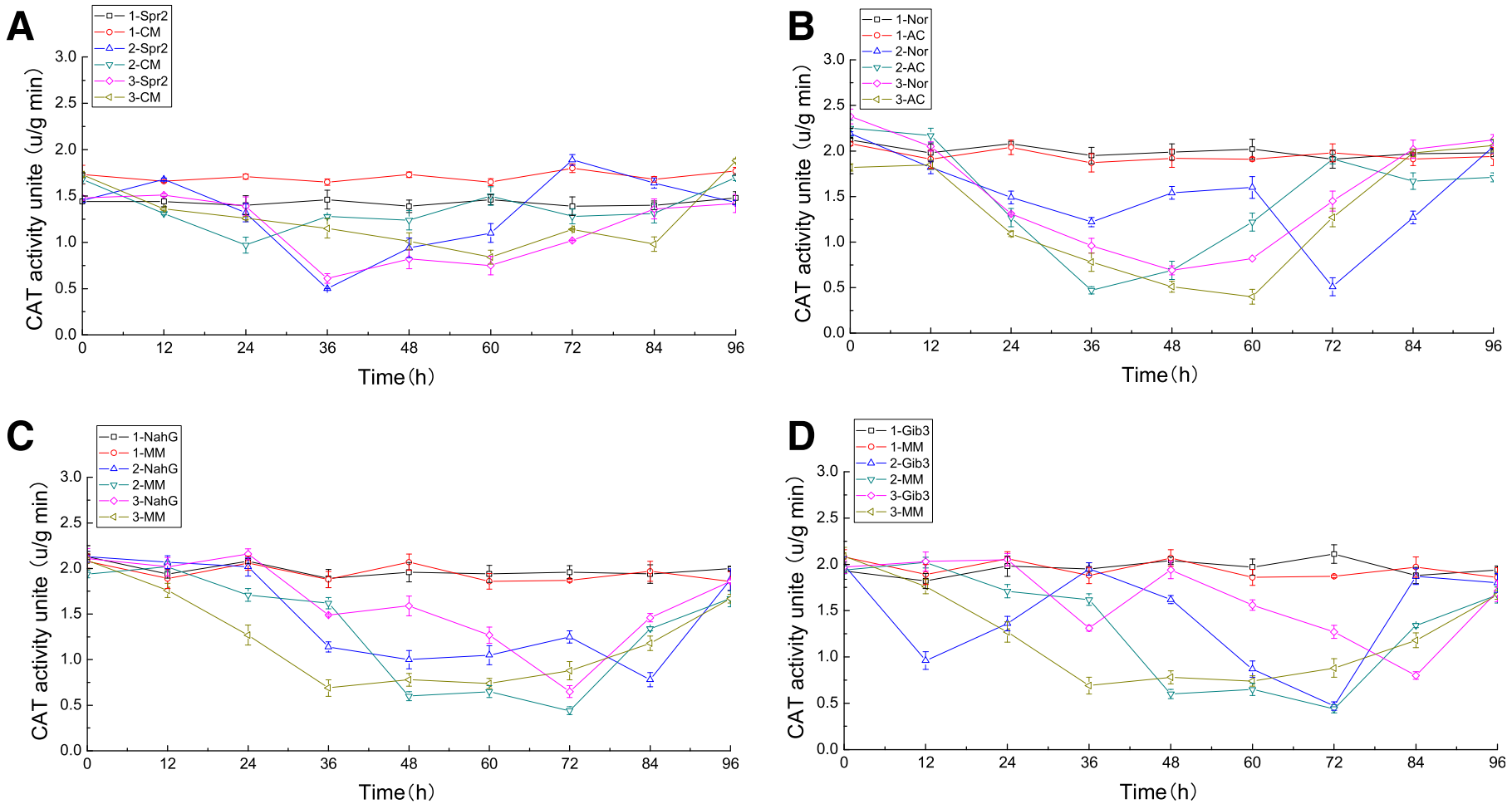

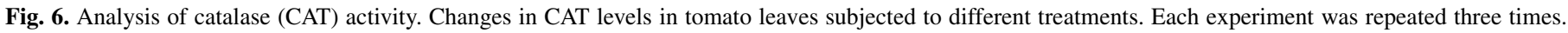

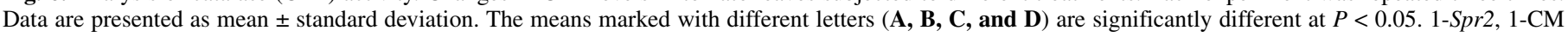

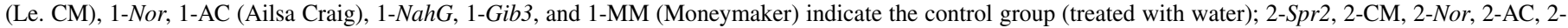

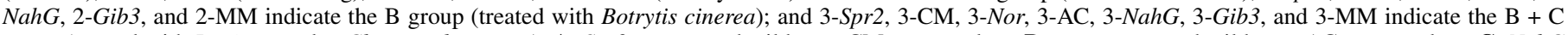

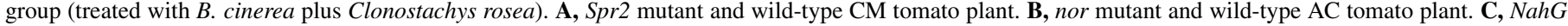
mutant and wild-type MM tomato plant. D, Gib3 mutant and wild-type MM tomato plant. 

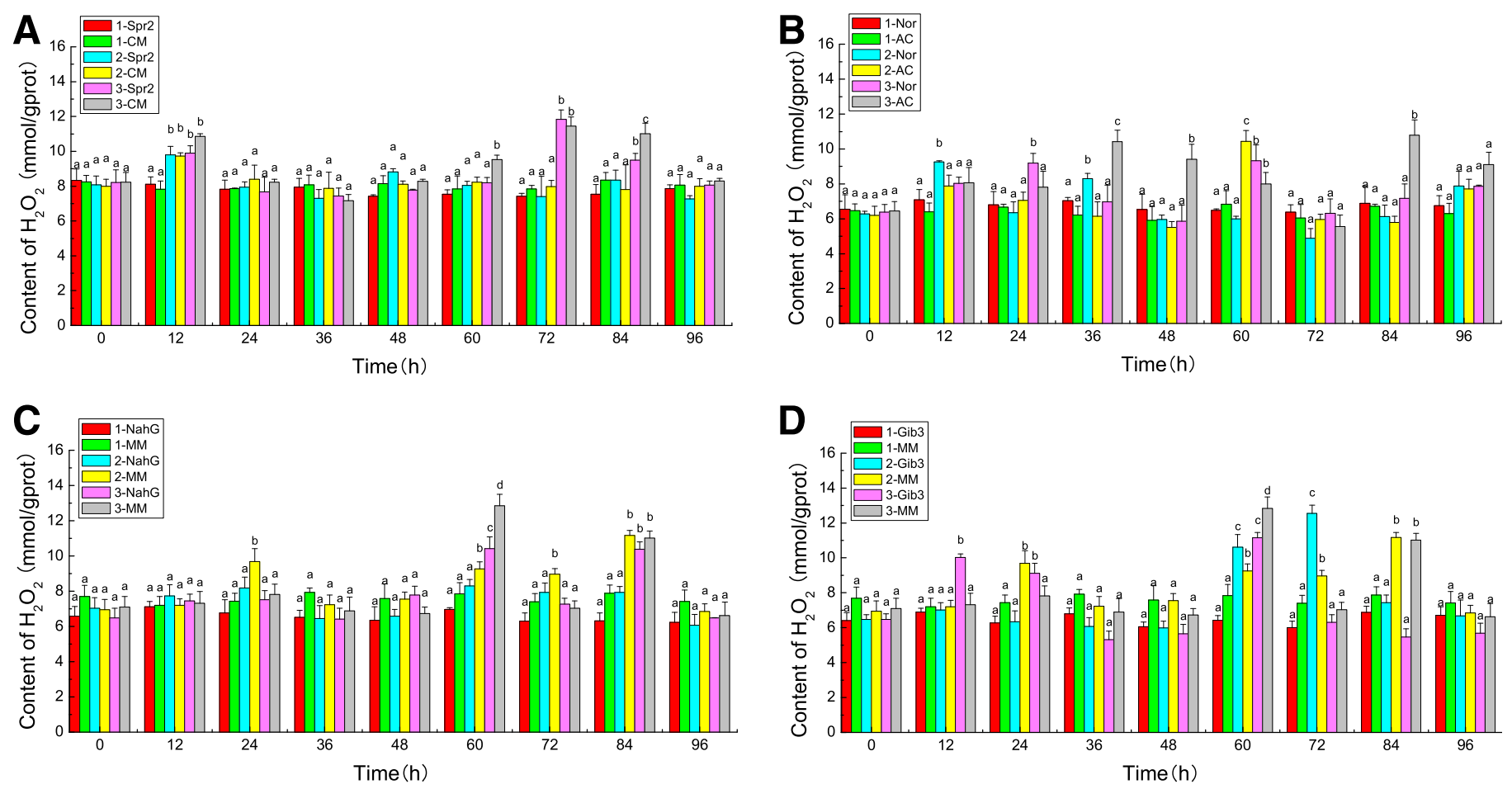

Fig. 7. Analysis of hydrogen peroxide $\left(\mathrm{H}_{2} \mathrm{O}_{2}\right)$ levels. Changes in $\mathrm{H}_{2} \mathrm{O}_{2}$ levels in tomato leaves subjected to different treatments. Each experiment was repeated three times. Data are presented as mean \pm standard deviation. The means marked with different letters $(\mathbf{A}, \mathbf{B}, \mathbf{C}$, and $\mathbf{D})$ are significantly different at $P<0.05 .1-S p r 2,1-\mathrm{CM}(\mathrm{Le}$. $\mathrm{CM}$ ), 1-Nor, 1-AC (Ailsa Craig), 1-NahG, 1-Gib3, and 1-MM (Moneymaker) indicate the control group (treated with water); 2-Spr2, 2-CM, 2-Nor, 2-AC, 2-NahG, 2-Gib3, and 2-MM indicate the B group (treated with Botrytis cinerea); and 3-Spr2, 3-CM, 3-Nor, 3-AC, 3-NahG, 3-Gib3, and 3-MM indicate the B + C group (treated with B. cinerea plus Clonostachys rosea). A, Spr2 mutant and wild-type CM tomato plant. B, nor mutant and wild-type AC tomato plant. C, NahG mutant and wild-type MM tomato plant. D, Gib3 mutant and wild-type MM tomato plant.
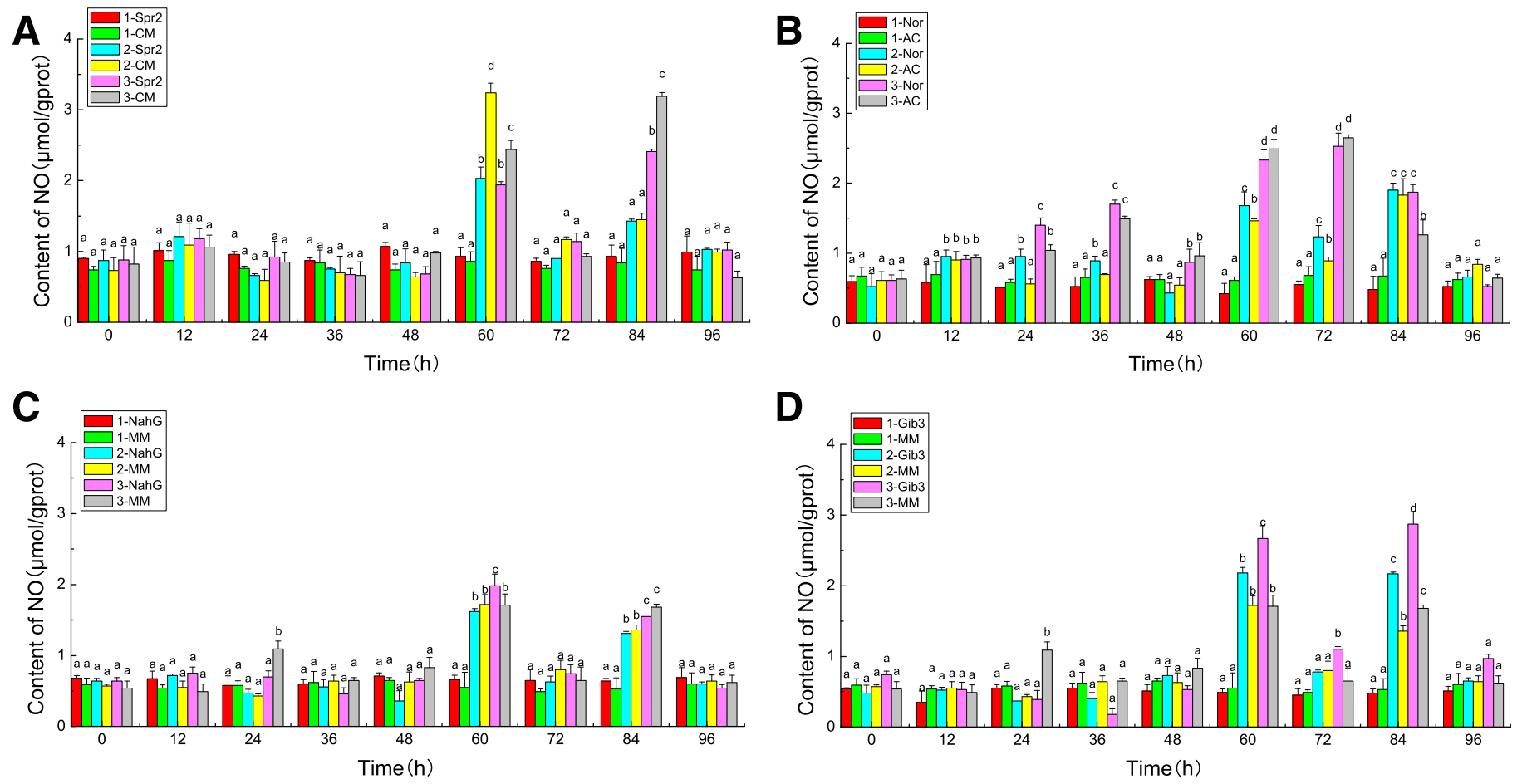

Fig. 8. Analysis of nitric oxide (NO) levels. Changes in NO levels in tomato leaves subjected to different treatments. Each experiment was repeated three times. Data are presented as mean \pm standard deviation. The means marked with different letters (A, B, C, and D) are significantly different at $P<0.05 .1-\mathrm{Spr} 2,1-\mathrm{CM}$ (Le. CM), 1Nor, 1-AC (Ailsa Craig), 1-NahG, 1-Gib3, and 1-MM (Moneymaker) indicate the control group (treated with water); 2-Spr2, 2-CM, 2-Nor, 2-AC, 2-NahG, 2-Gib3, and 2-MM indicate the B group (treated with Botrytis cinerea); and 3-Spr2, 3-CM, 3-Nor, 3-AC, 3-NahG, 3-Gib3, and 3-MM indicate the B + C group (treated with B. cinerea plus Clonostachys rosea). A, Spr 2 mutant and wild-type CM tomato plant. B, nor mutant and wild-type AC tomato plant. C, NahG mutant and wild-type MM tomato plant. D, Gib3 mutant and wild-type MM tomato plant. 
the wild type (Fig. 10B). In general, the $M A P K$ gene expression was higher in the wild type in the B $+\mathrm{C}$ group, except at $84 \mathrm{~h}$, in which the expression in the $\mathrm{B}$ group was significantly higher than that in the $\mathrm{B}+\mathrm{C}$ group.

No significant change in Lexyl expression was observed in the Spr2 mutant in the control group or B group. However, a
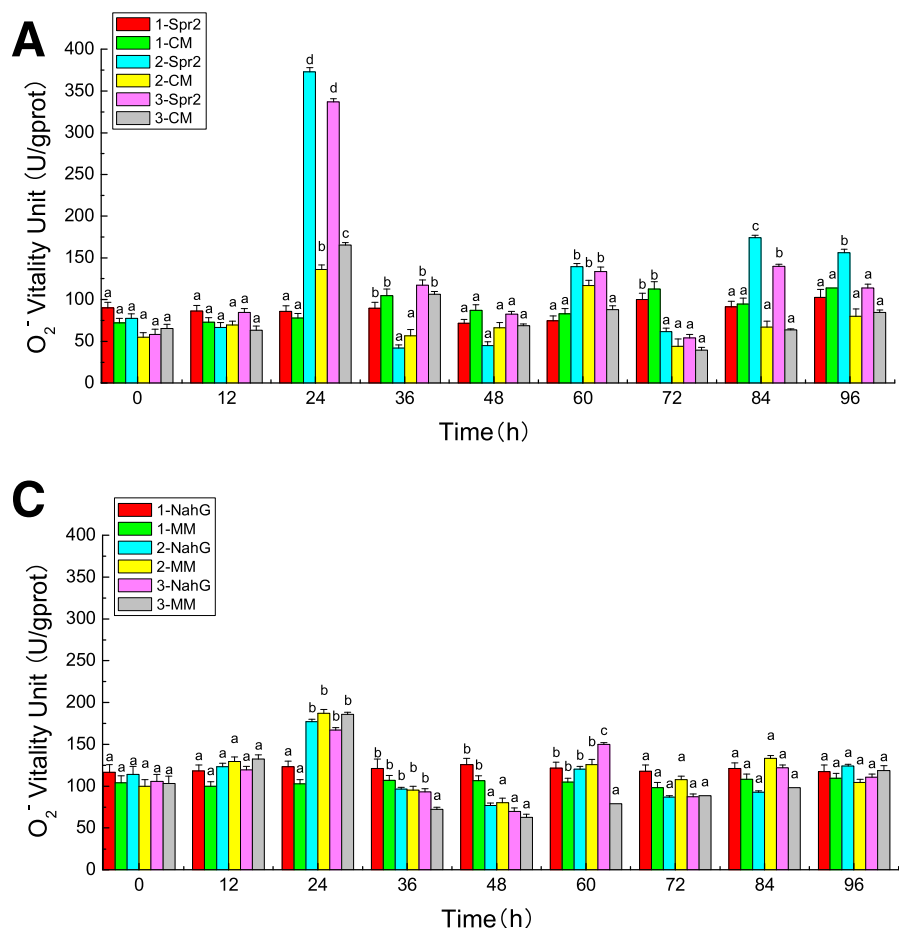

significant increase in Lexyl expression was observed in the B + $\mathrm{C}$ group, reaching its highest expression level at $36 \mathrm{~h}$ in the wild type (Fig. 10C). For the atpA expression, no significant changes were observed in the wild type in either the B group or the B $+\mathrm{C}$ group, except at $48 \mathrm{~h}$, where a significant increase was observed in the $\mathrm{B}+\mathrm{C}$ group. However, a significant increase was observed
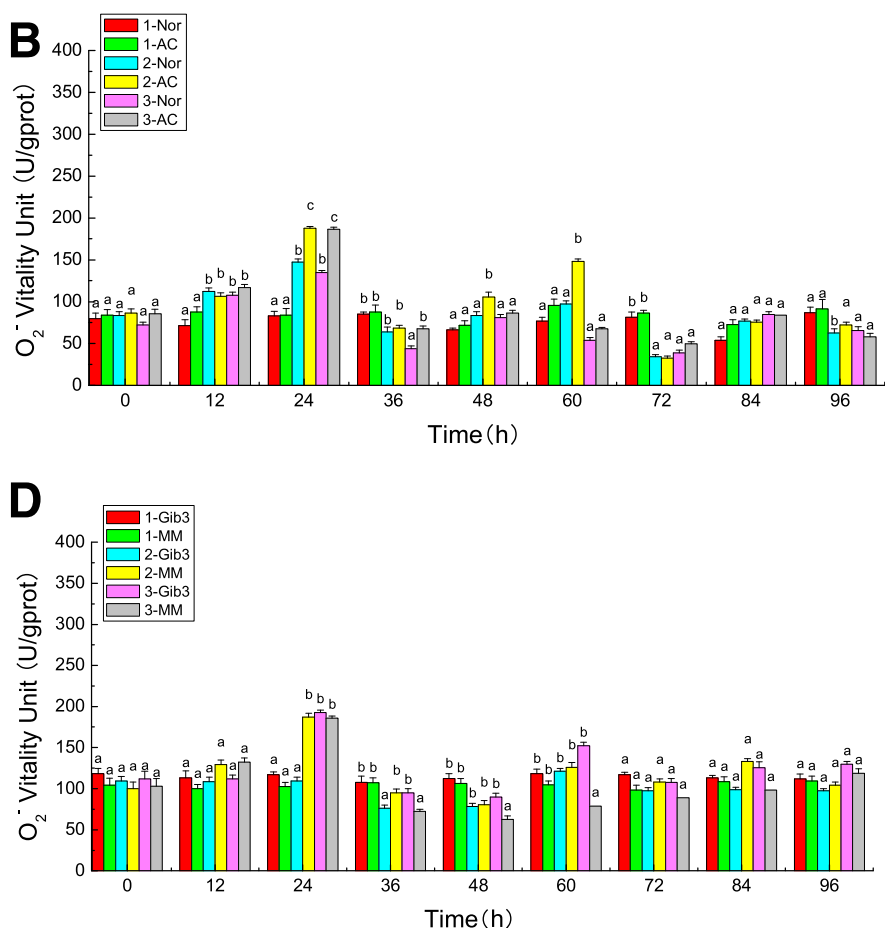

Fig. 9. Analysis of superoxide anion radical $\left(\mathrm{O}_{2}^{-}\right)$levels. Changes in $\mathrm{O}_{2}^{-}$levels in tomato leaves subjected to different treatments. Each experiment was repeated three times. Data are presented as mean \pm standard deviation. The means marked with different letters $(\mathbf{A}, \mathbf{B}, \mathbf{C}$, and $\mathbf{D})$ are significantly different at $P<0.05$. $1-$ Spr2, 1-CM (Le. CM), 1-Nor, 1-AC (Ailsa Craig), 1-NahG, 1-Gib3, and 1-MM (Moneymaker) indicate the control group (treated with water); 2-Spr2, 2-CM, 2Nor, 2-AC, 2-NahG, 2-Gib3, and 2-MM indicate the B group (treated with Botrytis cinerea); and 3-Spr2, 3-CM, 3-Nor, 3-AC, 3-NahG, 3-Gib3, and 3-MM indicate the B $+\mathrm{C}$ group (treated with B. cinerea plus Clonostachys rosea). A, Spr2 mutant and wild-type CM tomato plant. B, nor mutant and wild-type AC tomato plant. C, $N a h G$ mutant and wild-type MM tomato plant. D, Gib3 mutant and wild-type MM tomato plant.

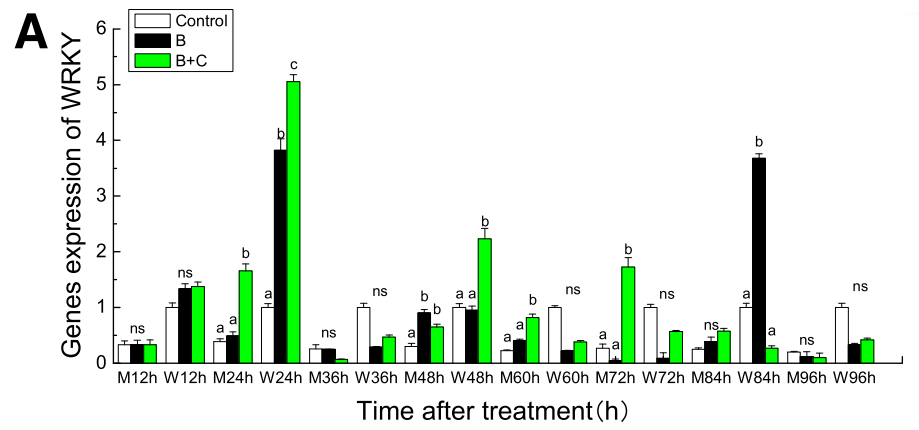

C

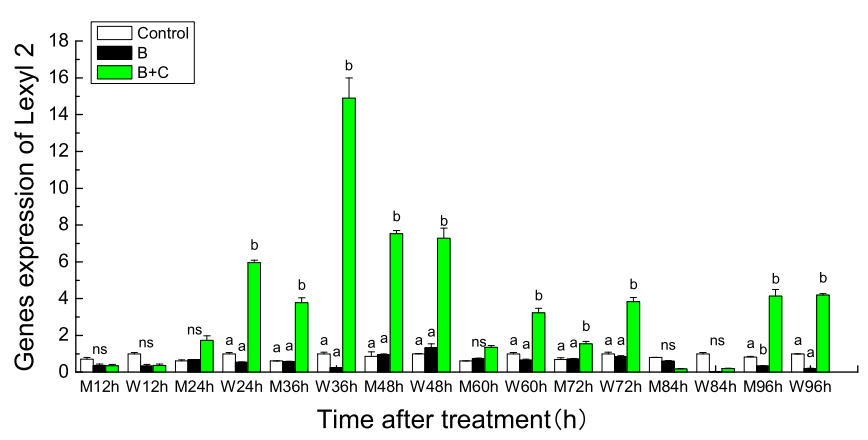

B

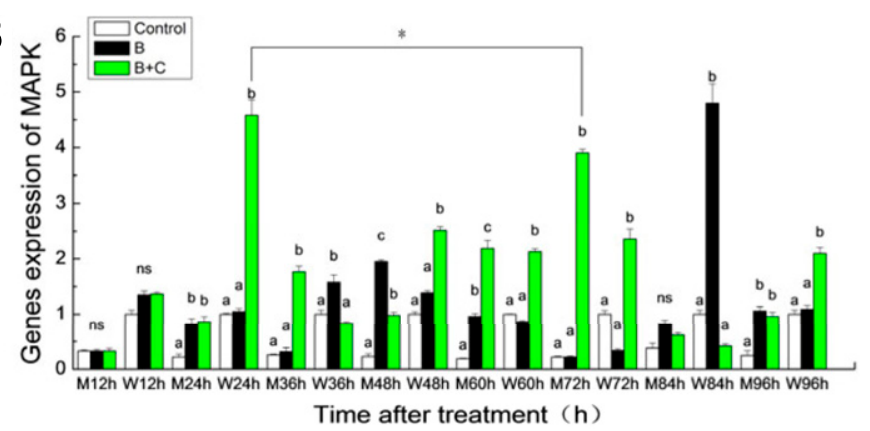

D

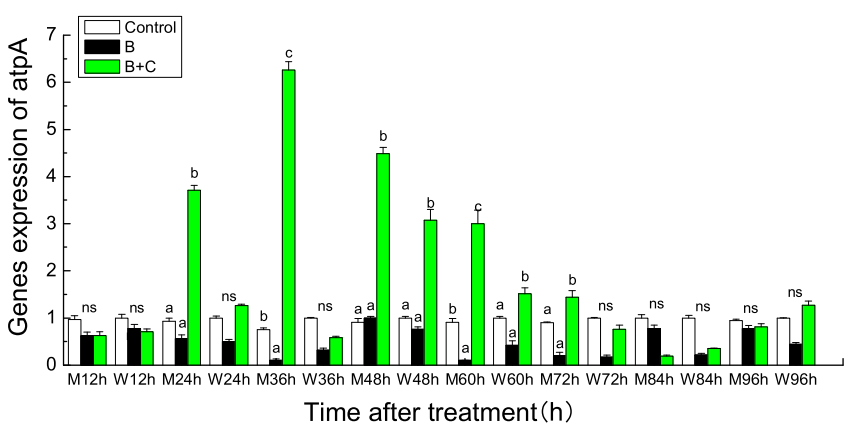

Fig. 10. Expression analysis of WRKY, mitogen-activated protein kinase (MAPK), Lexyl2, and atpA in the Spr2 mutant (indicated by M) and wild-type CM (Moneymaker) (indicated by W). Data are presented as mean \pm standard deviation. At each time point, the different letters indicate the significant differences between treatments $(P<0.05 ; n=9)$. ns, not significant. A, B, C, and $\mathbf{D}$ represent the expression of WRKY, MAPK, Lexyl2, and atpA genes, respectively. 
in the Spr2 mutant in the B $+\mathrm{C}$ group but not in the B group (Fig. 10D).

JA induces stomatal closure in tomato leaves at different treatments. The SEM analysis revealed that the stomatal opening ratio of the JA mutant $(S p r 2)$ treated with $B$. cinerea was significantly higher compared with that of CM (control, $P<0.01$ ) (Fig. 11A and Supplementary Fig. S2). At all time points, the stomatal opening ratio of the Spr2 mutant in the B $+\mathrm{C}$ group was also higher than that of $\mathrm{CM}(0$ to 10 days: $P<0.01 ; 12$ days: $P<$ 0.05) (Fig. 11B).

At 2, 6, and 12 days, the stomatal opening ratio of CM leaves in the $\mathrm{B}+\mathrm{C}$ group was significantly lower than that of $\mathrm{CM}$ leaves in the $\mathrm{B}$ group ( 2 and 6 days: $P<0.01 ; 12$ days: $P<0.05$ ). However, at 10 days, the opening ratio of the stomata of $\mathrm{CM}$ leaves in the $\mathrm{B}+\mathrm{C}$ group was significantly higher than that of the $\mathrm{CM}$ leaves in the $\mathrm{B}$ group $(P<0.01)$ (Fig. 11C).

At the time points of 2, 4, 8, and 10 days, the stomatal opening ratio of the Spr 2 mutant leaves in the B + C group was significantly higher than that in the $\mathrm{B}$ group $(2$ and 8 days: $P<0.05 ; 4$ and 10 days: $P<0.01)$. However, at 12 days, the opening ratio of the stomata of JA mutant leaves in the $\mathrm{B}+\mathrm{C}$ group was significantly lower than that in the B group $(P<0.01)$ (Fig. 11D).

\section{DISCUSSION}

C. rosea is a mycoparasitic fungus that can control several important plant diseases. It has the ability to parasitize and kill other fungi, such as $B$. cinerea, and utilize the dead fungal biomass (Karlsson et al. 2015). Compared with $B$. cinerea treatment, visible lesion was significantly reduced in the $B$. cinerea plus $C$. rosea treatment on tomato leaves, indicating the ability of $C$. rosea to resist $B$. cinerea in tomato leaves. In this study, it was demonstrated that $C$. rosea inhibits $B$. cinerea growth both in vivo and in vitro. In vitro, $C$. rosea completely blocked the growth of $B$. cinerea and spore germination. The spore germination experiment strongly suggested that $C$. rosea releases compounds that possess antibiotic properties and that these compounds may play a role in protecting plants from invading pathogens (Ezra et al. 2004). In vivo, it inhibits gray mold disease in both wild-type and mutant tomato plants.

Compared with the wild type, $C$. rosea treatment significantly changed several signal molecules in the mutants of Spr2, nor, and $N a h G$, suggesting that JA, ET, and SA are likely involved in the development of resistance to $B$. cinerea in tomato leaves.

Changes in defense enzymes in tomato leaves under C. rosea treatment. PAL, PPO, and CAT play important roles in protecting plants against various pathogens. PAL is involved in the phenylpropanoid pathway that takes part in the synthesis of phenolic compounds phytoalexin and lignin, which are important in pathogen resistance (Paiva et al. 1991; Pellegrini et al. 1994). PPO participates in the oxidation of many types of phenolic compounds, leading to the production of quinones, which are toxic to several pathogens (Thipyapong et al. 2004, 2007; Wang and Constabel 2004). In this study, it was found that B. cinerea-infected leaves triggered an increase in PAL and PPO activity. Furthermore, the treatment with $C$. rosea further enhanced the activity of PAL/ PPO enzymes. In addition, the activity of PAL/PPO in the wild type was significantly higher than that in the Spr2 mutant. However, the activity of PPO in the wild type was significantly lower than that in the nor mutant. Spr2 is involved in the biosynthesis pathway of JA, which is a positive regulator of PAL/PPO in the $C$. rosea-induced resistance to tomato gray mold disease. This is consistent with a previous study, which showed that JA can enhance the insect resistance of cotton seedlings by increasing the activity of PAL and other enzymes in cotton leaves (Yang et al. 2013). Methyl jasmonate has also been shown to significantly increase PPO levels (Boughton et al. 2006). However, PAL activity in NahG mutant plants was significantly higher compared with that of wild-type plants at several time points in either the $B$. cinerea-treated group or the $B$. cinerea- and $C$. rosea-treated group, suggesting that SA may play a negative role of PAL in $C$. rosea-induced resistance to tomato gray mold.

CAT is a key antioxidant enzyme that catalyzes the decomposition of cellular $\mathrm{H}_{2} \mathrm{O}_{2}$ and thereby, protects cells from oxidative stress. The $\mathrm{H}_{2} \mathrm{O}_{2}$ produced during electron transport in
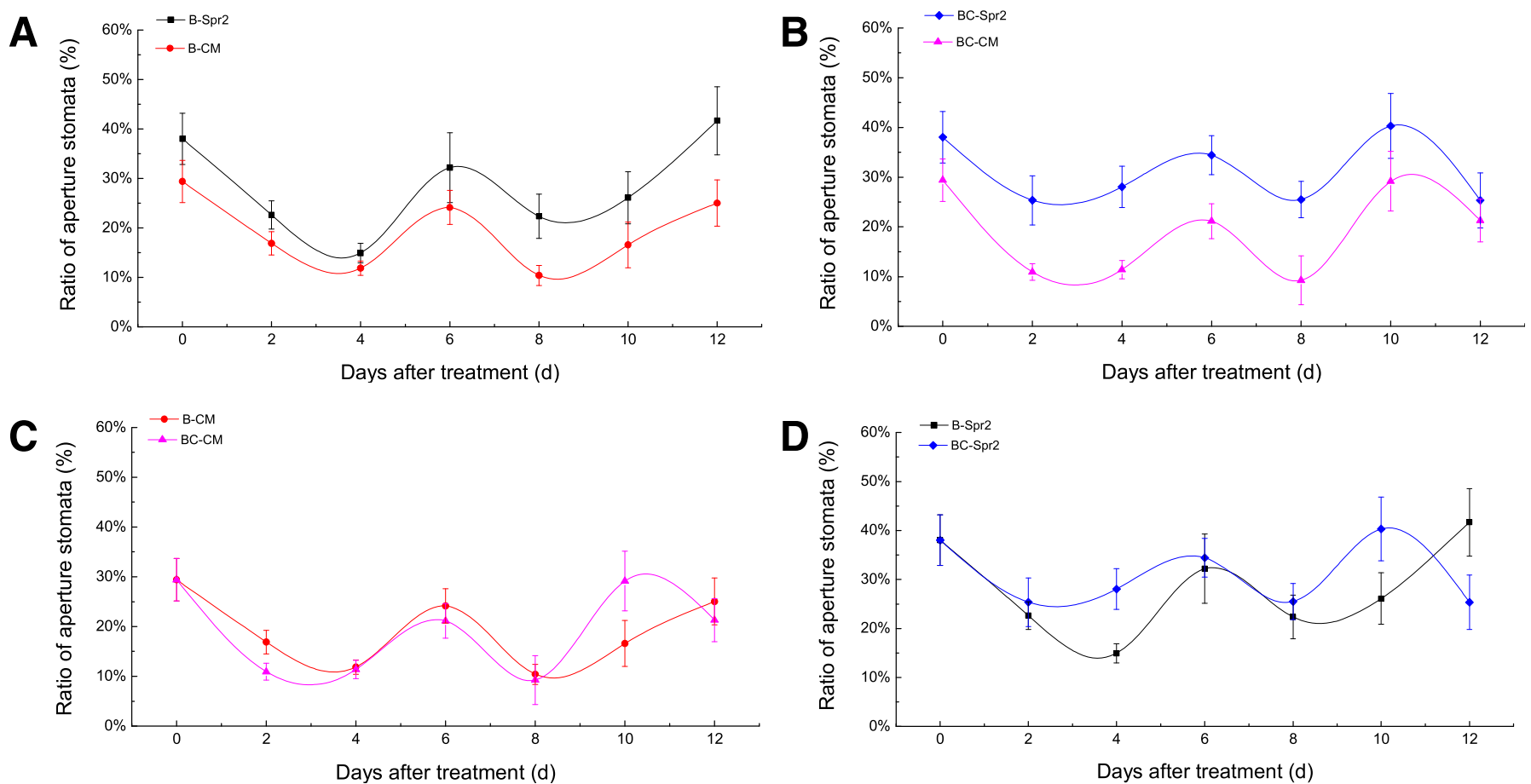

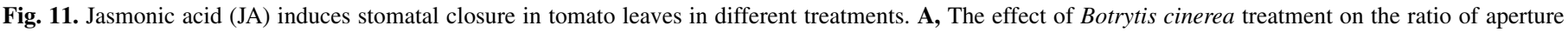

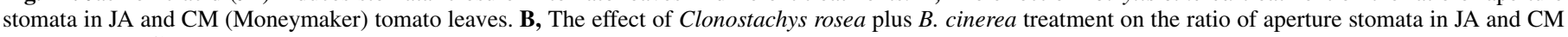

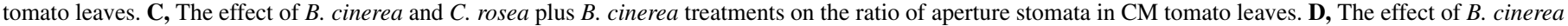
and $C$. rosea plus $B$. cinerea treatments on the ratio of aperture stomata in JA tomato leaves. 
mitochondria and the fatty acid $\beta$-oxidation process is mainly removed by CAT (Nan and Fan 2008; Tiwari et al. 2002). In this study, it was found that the activity of CAT enzyme in the Spr2 mutant was lower than that in the wild type, indicating that the Spr2 mutant enhances oxidative stress in plants because of the lack of JA, which may place the positive regulation of CAT in the C. roseainduced resistance to tomato gray mold disease. However, ET and $\mathrm{SA}$ may have a negative regulation of CAT. It has been reported that SA can increase the content of $\mathrm{H}_{2} \mathrm{O}_{2}$ and cause cell death (Hao et al. 2014; Mejía-Teniente et al. 2013).

Changes in second messengers in tomato leaves under C. rosea treatment. Redox homeostasis in plant cells is a key determinant of cell function. Imbalance of redox status leads to severe injury or cell death (Bykova and Rampitsch 2013; Vranova et al. 2002). Cell redox homeostasis closely correlates to accumulation of ROS (such as $\mathrm{H}_{2} \mathrm{O}_{2}$ and $\mathrm{O}_{2}^{-}$), which are important signaling molecules that participate in the regulation of physiological processes. Particularly, ROS play a significant role in plant resistance to pathogens by contributing to the induction of defense genes (Lehmann et al. 2015).

Rapid release of ROS is one of the early events known as oxidative burst (L'Haridon et al. 2011). It was found in this study that $B$. cinerea infection induced a high level of $\mathrm{O}_{2}^{-}$at $24 \mathrm{~h}$ among all four mutants and their wild types. The Spr 2 mutant produced a higher level of $\mathrm{O}_{2}^{-}$compared with the wild type in both the $B$. cinerea-treated group and the $B$. cinerea-plus $C$. rosea-treated group. However, the nor mutant produced a lower level of $\mathrm{O}_{2}^{-}$ compared with the wild type. These results suggest that JA may inhibit the accumulation of $\mathrm{O}_{2}^{-}$, where ET may promote the accumulation of $\mathrm{O}_{2}^{-}$. Furthermore, the $\mathrm{Spr} 2$, nor, and $N a h G$ mutants produced a lower level of $\mathrm{H}_{2} \mathrm{O}_{2}$ compared with their wild types in both the $B$. cinerea-treated group and the $B$. cinerea- plus $C$. roseatreated group. These results suggest that JA, ET, and SA may cause accumulation of $\mathrm{H}_{2} \mathrm{O}_{2}$. B. cinerea could produce oxalic acid, which can suppress the formation of ROS (Cessna et al. 2000; Prins et al. 2000). Compared with the control group or the B. cinerea-treated group, the $B$. cinerea-plus $C$. rosea-treated group produced more ROS, which enhanced the resistance of tomato toward $B$. cinerea infection. A similar phenomenon was reported in which the removal of oxalic acid produced by $B$. cinerea enhanced the protection of Arabidopsis thaliana (Schoonbeek et al. 2007).

$\mathrm{NO}$ is a regulator of physiological processes and functions as a messenger in immune response. NO also promotes seed germination and root growth, and it prolongs leaf elongation (Palavan-Unsal and Arisan 2009). As a regulator of disease resistance, it can initiate the death of hypersensitive cells and activate the expression of a series of defense genes (Hong et al. 2008).

In this study, it was revealed that the wild type (CM) produced a higher level of NO compared with the Spr2 mutant, suggesting that JA may promote the accumulation of NO during $B$. cinerea infection. This is consistent with a previous report in which JA treatment induced the production of NO (Casimiro et al. 2001). It was also found that the effect of NO levels was higher in the $B$. cinerea plus $C$. rosea treatment than in other treatments.

Changes in the expression of MAPK and WRKY in the Spr2 mutant and its wild type. The $M A P K$ gene family and the $W R K Y$ transcription factor family play an important role in plant growth and other physiological and biochemical processes (Rushton et al. 2010; Ülker and Somssich 2004). Studies on early events after pathogen recognition have established the importance of MAPK and WRKYs in plant defense response (Mouekouba et al. 2014).

In this study, the JA signaling pathway was selected to investigate the role of these two genes in $C$. rosea-induced resistance to tomato gray mold disease. It was found that the expression of $M A P K$ and $W R K Y$ was higher under $B$. cinerea plus $C$. rosea treatment and that
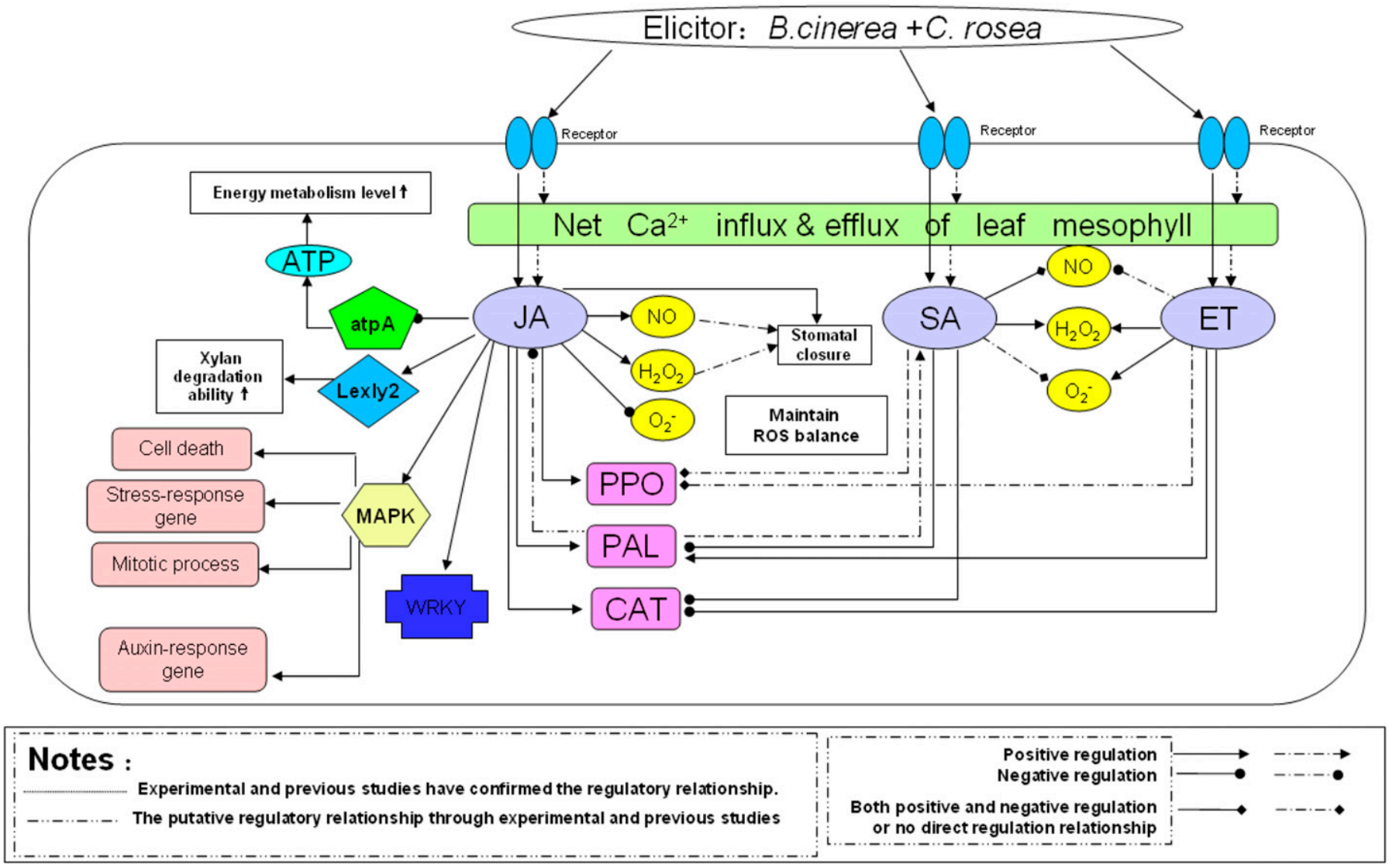

Fig. 12. The potential signaling pathway model of Clonostachys rosea primed the innate immunity to tomato gray mold disease in mesophyll cells. B. cinerea, Botrytis cinerea; CAT, catalase; ET, ethylene; $\mathrm{H}_{2} \mathrm{O}_{2}$, hydrogen peroxide; JA, jasmonic acid; MAPK, mitogen-activated protein kinase; NO, nitric oxide; $\mathrm{O}_{2}^{-}$, superoxide anion radical; PAL, phenylalanine ammonialyase; PPO, polyphenol oxidase; ROS, reactive oxygen species; SA, salicylic acid. 
these two genes were expressed lower in the Spr 2 mutant than in the wild type, suggesting that JA may promote the expression of WRKY and $M A P K$ via the production of NO. A model for the potential signaling pathway is illustrated in Figures 11 and 12.

Changes in the expression of $L E X Y 2$ and $a t p A$ in the Spr 2 mutant and its wild type. $\beta$-xylanase (encoded by Lexyl2) is one of the key enzymes of xylan degradation. Xylan degradation could be used to modify the plant cell wall structure in response to infection. However, little is known about the role of $\beta$-xylanase in the $C$. rosea-induced resistance to $B$. cinerea infection in tomato. It was found that $B$. cinerea plus $C$. rosea treatment induced Lexyl 2 expression in either the wild-type or Spr2 leaves. This is in agreement with a previous study (Mouekouba et al. 2014). It was also revealed that JA upregulates Lexyl2 expression in B. cinerea plus $C$. rosea treatment, suggesting that Lexyl2 may play an important role in $C$. rosea-induced resistance to $B$. cinerea, possibly by modifying the cell wall structure.

The ATP synthase CF1 $\alpha$-subunit is a photosynthetic-related protein (Shao et al. 2011) that is located on the chloroplast membrane. ATPase plays an important role in promoting plant resistance to abiotic and biotic stress (Chen et al. 2000; Wu et al. 2013). It is encoded by the atpA gene on the chloroplast genome, and it is relatively conservative in evolution and low in mutation rate (Singh et al. 1985). It triggers a series of resistance reactions by proton transportation, improving cytoplasmic $\mathrm{pH}$. The ATP synthase CF1 $\alpha$-subunit also facilitates energy increase to enhance the resistance of plants (Shao et al. 2011). It was found that $B$. cinerea plus $C$. rosea treatment induced a higher level of atpA expression compared with the control group or the $B$. cinereatreated group. It was also revealed that the atpA levels of the Spr2 mutant were significantly higher than those of the wild type in the $B$. cinerea- plus $C$. rosea-treated group, suggesting that JA inhibits atpA expression.

JA induces stomatal closure in tomato leaves in different treatments. The stomatal aperture in leaf epidermis is formed by a pair of guard cells, which regulate opening and closing of the aperture. Many factors, such as light, drought, external $\mathrm{Ca}^{2+}, \mathrm{SA}$, and MeJA, could affect the opening/closing of apertures, which helps the plant to control transpiration, gas exchange, and innate immunity (Prodhan et al. 2018). Previous studies demonstrated that guard cells can sense microbes and close the pore, a process known as stomatal defense or stomatal immunity.

This study revealed that the stomatal opening ratio of leaves significantly increased when JA was absent in either $B$. cinerea treatment alone or the $B$. cinerea plus $C$. rosea treatment in tomato leaves. This suggests that JA effectively induces stomatal closure. In addition, $C$. rosea treatment caused stomatal closure at the early stage of the disease. The stomatal opening ratio decreased significantly at 2 to 4 days after inoculation, and the number of closed stomata increased. Significant changes of $\mathrm{H}_{2} \mathrm{O}_{2}$ and $\mathrm{NO}$ also occurred at the same time. In the $\mathrm{B}+\mathrm{C}$ treatment, $\mathrm{H}_{2} \mathrm{O}_{2}$ increased from $60 \mathrm{~h}$ and peaked at $72 \mathrm{~h}$, whereas NO peaked at 60 and $84 \mathrm{~h}$ (Figs. 8 and 9). C. rosea promotes the production of $\mathrm{H}_{2} \mathrm{O}_{2}$ and NO, which may induce the contraction of guard cells in leaves, thus accelerating stomatal closure. The effect of $\mathrm{H}_{2} \mathrm{O}_{2}$ and $\mathrm{NO}$ on stomata is consistent with that shown in previous studies (Desikan et al. 2006; Xie et al. 2014). The levels of PAL and PPO also increased at the early stage of disease ( 2 to 4 days), which correlates with the increased stomata closure. These two enzymes may have a high correlation with stomatal regulation in the model of $C$. rosea primed the innate immunity. Among the genes (WRKY, MAPK, Lexyl2, and atpA) that we tested, only MAPK showed a positive correlation with stomatal closure rate. In the later period of disease resistance, the expression of CAT could be directly or indirectly increased, and the stability of $\mathrm{H}_{2} \mathrm{O}_{2}$ was inhibited, whereas the opening of the stomata increased. Additional studies are needed to understand how these factors regulate stomatal opening and closure by regulating the related second messengers, such as $\mathrm{Ca}^{2+}, \mathrm{H}_{2} \mathrm{O}_{2}$, and $\mathrm{NO}$, in $C$. rosea-induced innate immunity against tomato gray mold disease.

Based on these data and previous studies, a model was proposed for the possible roles of JA, ET, and SA in the signaling pathway of C. rosea-induced resistance to gray mold disease in tomato (Fig. 12). JA, ET, or SA response enhances the resistance to $B$. cinerea infection. However, GA is likely not involved in the process, because the disease symptoms in GA mutants were indistinguishable from those of wild-type plants.

In conclusion, it was revealed that $C$. rosea-induced resistance to $B$. cinere $a$ is affected by multiple factors, including protective enzymes (PAL, PPO, and CAT), the levels of ROS and NO, and the expression of several stress response genes (MAPK, WRKY, Lexyl2, and atpA). All of these are affected by hormone-related genes, especially $S p r 2$. This study sheds new light on the molecular mechanism of $C$. rosea-induced resistance to gray mold disease in tomato.

\section{ACKNOWLEDGMENT}

We thank Medjaden Bioscience Limited for the scientific and English editing of this manuscript.

\section{LITERATURE CITED}

Abuqamar, S., Chai, F., Luo, H., Song, F., and Mengiste T. 2008. Tomato protein kinase $1 \mathrm{~b}$ mediates signaling of plant responses to necrotrophic fungi and insect herbivory. Plant Cell. 20:1964-1983.

Berri, S., Abbruscato, P., Faivre-Rampant, O., Brasileiro, A.C.M., Fumasoni, I., Satoh, K., Kikuchi, S., Mizzi, L., Morandini, P., Pè, M. E., and Piffanelli, P. 2009. Characterization of WRKY co-regulatory networks in rice and Arabidopsis. BMC Plant Biol. 9:120.

Boughton, A. J., Hoover, K., and Felton, G. W. 2006. Impact of chemical elicitor applications on greenhouse tomato plants and population growth of the green peach aphid, Myzus persicae. Entomol. Exp. Appl. 120:175-188.

Bykova, N. V., and Rampitsch, C. 2013. Modulating protein function through reversible oxidation: Redox-mediated processes in plants revealed through proteomics. Proteomics 13:579-596.

Casimiro, I., Marchant, A., Bhalerao, R. P., Beeckman, T., Dhooge, S., Swarup, R., Graham, N., Inzé, D., Sandberg, G., Casero, P. J., and Bennett, M. 2001. Auxin transport promotes Arabidopsis lateral root initiation. Plant Cell 13:843-852.

Celedonio, G., Nélida, B., and Amir, S. 2016. Infection process and fungal virulence factors. Pages 229-246 in: Botrytis-the Fungus, the Pathogen and Its Management in Agricultural Systems, F. Sabine and E. Yigal, eds. Springer, Cham, Switzerland.

Cessna, S. G., Sears, V. E., Dickman, M. B., and Low, P. S. 2000. Oxalic acid, a pathogenicity factor for Sclerotinia sclerotiorum, suppresses the oxidative burst of the host plant. Plant Cell 12:2191-2200.

Chen, Y.-H., Shen, Z.-G., and Liu, Y.-L. 2000. Effects of chilling and high pH stresses on the ATPase activities of plasma membrane and tonoplast vesicles isolated from rice (Oryza sativa L.) roots. Acta Phytophysiol. Sin. 05:407-412.

Desikan, R., Last, K., Harrett-Williams, R., Tagliavia, C., Harter, K., Hooley, R., Hancock, J. T., and Neill, S. J. 2006. Ethylene-induced stomatal closure in Arabidopsis occurs via AtrbohF-mediated hydrogen peroxide synthesis. Plant J. 47:907-916.

Elad, Y., Vivier, M., and Fillinger, S. 2015. Botrytis, the good, the bad and the ugly. Pages 1-15 in: Botrytis - the Fungus, the Pathogen and Its Management in Agricultural Systems, S. Fillinger and Y. Elad, eds. Springer, Cham, Switzerland.

Ezra, D., Hess, W. M., and Strobel, G. A. 2004. New endophytic isolates of Muscodor albus, a volatile-antibiotic-producing fungus. Microbiology 150: 4023-4031.

Fang, Z. 2007. Research Methods of Plant Diseases. Chinese Agricultural Press, Beijing, China.

Gajera, H. P., and Vakharia, D. N. 2010. Molecular and biochemical characterization of Trichoderma isolates inhibiting a phytopathogenic fungi Aspergillus niger Van Tieghem. Physiol. Mol. Plant Pathol. 74:274-282.

García, N., González, M. A., González, C., and Brito, N. 2017. Simultaneous silencing of xylanase genes in Botrytis cinerea. Front. Plant Sci. 8:2174.

Gong, C. 2017. Page 114 in: Expression Analysis of atpA Gene From Tomato and Functional Characterization of atpA-Overexpression Tobacco in Response to Different Stresses. Northeast Agricultural University, Harbin, Heilongjiang, China.

Hao, T., Song, H., Cui, L., and Wang, X. 2017. Observation of soybean nodule by scanning electron microscope. J. Chin. Electron. Microsc. Soc. 36: $167-172$. 
Hao, W., Guo, H.-b., Zhang, J., Hu, G., Yao, Y., Dong, J. 2014. Hydrogen peroxide is involved in salicylic acid-elicited rosmarinic acid production in Salvia miltiorrhiza cell cultures. Sci. World J. 2014:1-7.

Hong, J. K., Yun, B.-W., Kang, J.-G., Raja, M. U., Kwon, E., Sorhagen, K., Chu, C., Wang, Y., and Loake, G. J. 2008. Nitric oxide function and signalling in plant disease resistance. J. Exp. Bot. 59:147-154.

Karlsson, M., Durling, M. B., Choi, J., Kosawang, C., Lackner, G., Tzelepis, G. D., Nygren, K., Dubey, M. K., Kamou, N., Levasseur, A., Zapparata, A., Wang, J., Amby, D. B., Jensen, B., Sarrocco, S., Panteris, E., Lagopodi, A. L., Pöggeler, S., Vannacci, G., Collinge, D. B., Hoffmeister, D., Henrissat, B., Lee, Y.-H., and Jensen, D. F. 2015. Insights on the evolution of mycoparasitism from the genome of Clonostachys rosea.Genome Biol. Evol. 7:465-480.

Lehmann, S., Serrano, M., L'Haridon, F., Tjamos, S. E., and Metraux, J.-P. 2015. Reactive oxygen species and plant resistance to fungal pathogens. Phytochemistry 112:54-62.

Lemonnier, P., Gaillard, C., Veillet, F., Verbeke, J., Lemoine, R., Coutos-Thévenot, P., and La Camera, S. 2014. Expression of Arabidopsis sugar transport protein STP13 differentially affects glucose transport activity and basal resistance to Botrytis cinerea. Plant Mol. Biol. 85:473-484.

L'Haridon, F., Besson-Bard, A., Binda, M., Serrano, M., Abou-Mansour, E., Balet, F., Schoonbeek, H.-J., Hess, S., Mir, R., Léon, J., Lamotte, O., and Métraux, J.-P. 2011. A permeable cuticle is associated with the release of reactive oxygen species and induction of innate immunity. PLoS Pathog 7:e1002148.

Li, H. 2000. Principles and Techniques of Plant Physiology and Biochemistry. Higher Education Press, Beijing, China.

Liu, W., Song, S., and Shen, X. 2013. Screening, identification and antibacterial activity of antagonistic bacteria LW-6-1 against Botrytis cinerea. J. Northwest Agric. For. Univ. 41:73-79.

Livak, K. J., and Schmittgen, T. D. 2001. Analysis of relative gene expression data using real-time quantitative PCR and the 2(-Delta C(T)) Method. Methods 25:402-408.

Mai, V. C., Drzewiecka, K., Jelen, H., Narożna, D., Rucińska-Sobkowiak, R., Kęsy, J., Floryszak-Wieczorek, J., Gabryś, B., and Morkunas, I. 2014. Differential induction of Pisum sativum defense signaling molecules in response to pea aphid infestation. Plant Sci. 221-222:1-12.

Masmoudi, F., Ben Khedher, S., Kamoun, A., Zouari, N., Tounsi, S., and Trigui, M. 2017. Combinatorial effect of mutagenesis and medium component optimization on Bacillus amyloliquefaciens antifungal activity and efficacy in eradicating Botrytis cinerea. Microbiol. Res. 197:29-38.

Mejía-Teniente, L., de Dalia Durán-Flores, F., Chapa-Oliver, A. M., Torres-Pacheco, I., Cruz-Hernández, A., González-Chavira, M. M., Ocampo-Velázquez, R. V., and Guevara-González, R. G. 2013. Oxidative and molecular responses in Capsicum annиum L. after hydrogen peroxide, salicylic acid and chitosan foliar applications. Int. J. Mol. Sci. 14: 10178-10196.

Mengiste, T. 2012. Plant immunity to necrotrophs. Annu. Rev. Phytopathol. 50:267-294

Mouekouba, L. D. O., Xhang, L., Guan, X., Chen, X., Chen, H., Zhang, J., Zhang, J., Li, J., Yang, Y., and Wang, A. 2014. Analysis of Clonostachys rosea-induced resistance to tomato gray mold disease in tomato leaves. PLoS One 9:e102690.

Nan, R., and Fan, Y. 2008. Advance of researches on catalase in plants. Anhui Agric. Sci. Bull. 05:27-29.

Paiva, N. L., Edwards, R., Sun, Y., Hrazdina, G., and Dixon, R. A. 1991. Stress responses in alfalfa (Medicago sativa L.) 11. Molecular cloning and expression of alfalfa isoflavone reductase, a key enzyme of isoflavonoid phytoalexin biosynthesis. Plant Mol. Biol. 17:653-667.

Palavan-Unsal, N., and Arisan, D. 2009. Nitric oxide signalling in plants. Bot. Rev. 75:203-229.

Pellegrini, L., Rohfritsch, O., Fritig, B., and Legrand, M. 1994. Phenylalanine ammonia-lyase in tobacco. Molecular cloning and gene expression during the hypersensitive reaction to tobacco mosaic virus and the response to a fungal elicitor. Plant Physiol. 106:877-886.

Ponce, L., Eric, A., Carina, G, Alexandra, C., Alfonso, A., and Marcos, M. 2012. Physcomitrella patens activates reinforcement of the cell wall, programmed cell death and accumulation of evolutionary conserved defence signals, such as salicylic acid and 12-oxo-phytodienoic acid, but not jasmonic acid, upon Botrytis cinerea infection. Mol. Plant Pathol. 13:960-974.
Prins, T. W., Tudzynski, P., von Tiedemann, A., Tudzynski, B., Ten Have, A., Hansen, M. E., Tenberge, K., and van Kan, J. A. 2000. Infection strategies of Botrytis cinerea and related necrotrophic pathogens. Pages 33-64 in: Fungal Pathology. J. W. Kronstad, ed. Kluwer Academic Publishers, Dordrecht, The Netherlands.

Prodhan, M. Y., Munemasa, S., Nahar, M. N.-E.-N., Nakamura, Y., and Murata, Y. 2018. Guard cell salicylic acid signaling is integrated into abscisic acid signaling via the $\mathrm{Ca}+/ \mathrm{CPK}$-dependent pathway. Plant Physiol. 178:441-450.

Quazi, S. A. J., Meon, S., Jaafar, H., and Ahmad, Z. A. B. M. 2015. The role of phytohormones in relation to bakanae disease development and symptoms expression. Physiol. Mol. Plant Pathol. 90:27-38.

Ramamoorthy, R., Jiang, S. Y., Kumar, N., Venkatesh, P. N., and Ramachandran, S. 2008. A comprehensive transcriptional profiling of the WRKY gene family in rice under various abiotic and phytohormone treatments. Plant Cell Physiol. 49:865-879.

Rushton, P. J., Somssich, I. E., Ringler, P., and Shen, Q. J. 2010. WRKY transcription factors. Trends Plant Sci. 15:247-258.

Schoonbeek, H.-j., Jacquat-Bovet, A.-C., Mascher, F., and Métraux, J.-P. 2007. Oxalate-degrading bacteria can protect Arabidopsis thaliana and crop plants against Botrytis cinerea. Mol. Plant-Microbe Interact. 20:1535-1544

Shao, H., Cao, Q., Tao, X., Gu, Y., Chang, M., and Huang, C. 2011. Cloning and characterization of ATP synthase CF1 alpha gene from sweet potato. Afr. J. Biotechnol. 10:19035-19042.

Shu, X., An, D., Zhang, Q., and Chi, M. A. 2004. Election and identification of antagonistic actinomycetes S-5210-6 from soil. J. Northwest Agric. For. Univ. 12:57-60.

Singh, G. P., Wallen, D. G., and Pillay, D. T. 1985. Positioning of proteincoding genes on the soybean chloroplast genome. Plant Mol. Biol. 4:87-93.

Thipyapong, P., Hunt, M. D., and Steffens, J. C. 2004. Antisense downregulation of polyphenol oxidase results in enhanced disease susceptibility. Planta 220:105-117.

Thipyapong, P., Stout, M. J., and Attajarusit, J. 2007. Functional analysis of polyphenol oxidases by antisense/sense technology. Molecules 12: 1569-1595.

Tiwari, B. S., Belenghi, B., and Levine, A. 2002. Oxidative stress increased respiration and generation of reactive oxygen species, resulting in ATP depletion, opening of mitochondrial permeability transition, and programmed cell death. Plant Physiol. 128:1271-1281.

Ülker, B., and Somssich, I. E. 2004. WRKY transcription factors: From DNA binding towards biological function. Curr. Opin. Plant Biol. 7:491-498.

Vranova, E., Inze, D., and Van Breusegem, F. 2002. Signal transduction during oxidative stress. J. Exp. Bot. 53:1227-1236.

Wang, A., Zhang, L., Wang, X., Qu, W., Kong, L., and Chen, X. 2015. Study on growth-promoting effects and application patterns of Clonostachys rosea in tomato. J. Northeast Agric. Univ. 46:37-44.

Wang, J., and Constabel, C. P. 2004. Polyphenol oxidase overexpression in transgenic Populus enhances resistance to herbivory by forest tent caterpillar (Malacosoma disstria). Planta 220:87-96.

Wang, R. 2013. Clonostachys rosea induced non-host resistance to gray mould disease in tomato. Masters dissert. Northeast Agricultural University, Harbin, China.

Wu, L., Wang, S., Chen, X., Wang, X., Wu, L., Zu, X., Chen, Y. 2013. Proteomic and phytohormone analysis of the response of maize (Zea mays L.) seedlings to sugarcane mosaic virus. PLoS One 8:e70295.

Xie, Y., Mao, Y., Zhang, W., Lai, D., Wang, Q., and Shen, W. 2014. Reactive oxygen species-dependent nitric oxide production contributes to hydrogen-promoted stomatal closure in Arabidopsis. Plant Physiol. 165:759-773.

Yang, S., Wang, M., and Xie, J. 2013. Induction effects of jasmonic acid on tannin content and defense-related enzyme activities in conventional cotton plants. Acta Ecol. Sin. 33:1615-1625.

Zhang, X., Dai, Y., Xiong, Y., DeFraia, C., Li, J., Dong, X., and Mou, Z. 2007. Overexpression of Arabidopsis MAP kinase 7 leads to activation of plant basal and systemic acquired resistance. Plant J. 52:1066-1079.

Zong, Z. F., Wei, Y. H., Gao, L., Xue, Y., and Yang, Z. W. 2003. Effects of chitin degradation actinomycetes on cotton Fusarium wilt and Verticillium dahlia. J. Northwest Agric. For. Univ. 31:63-65. 